PontIFícIa UniVERSIDADE CATÓLICA dO RIO DE JANEIRO

Análise das relações de consumo de bolsa de luxo da marca Michael Kors entre as mulheres das classes de renda $A$, $B$ e $C$

Vanessa Gonçalves de Abreu

Trabalho de Conclusão de Curso

Centro de Ciências socials - CCS

DePARTAMENTO de AdMINISTRAÇÃo

Graduação em Administração de Empresas 
Vanessa Gonçalves de Abreu

\section{Análise das relações de consumo de bolsa de luxo da marca Michael Kors entre as mulheres das classes de renda $A, B$ e $C$}

Trabalho de Conclusão de Curso

Trabalho de Conclusão de Curso, apresentado ao programa de graduação em Administração da PUC-Rio como requisito parcial para a obtenção do titulo de graduação em Administração.

Orientador(a) : João Renato de Souza Coelho Benazzi

Rio de Janeiro,

Novembro de 2016. 


\section{Agradecimentos}

Primeiramente a Deus, que por mais que eu não possa vê-lo sei que sempre está presente em todos os momentos e nunca me deixou desistir durante toda a caminhada da graduação.

À minha família em especial meus pais Artemisio e Antonieta e ao meu irmãozinho Gabriel que por mais complicados que sejam, sempre me motivaram a alcançar um diploma de uma excelente universidade, onde o meu maior objetivo sempre foi orgulhá-los.

Em especial agradeço ao meu namorado Adriano, que neste período esteve mais presente na minha vida pessoal, consequentemente acadêmica. Aos meus mais que amigos, irmãos André Luiz e Ana Claudia que passaram por tudo que se possa imaginar comigo no decorrer da faculdade. Com toda a certeza apenas o inicio de uma grande irmandade.

Agradeço a muitas pessoas que passaram pelo meu caminho no decorrer desses anos, mas citá-las seria ao mesmo tempo extenso e injusto, pois poderia esquecer-me de mencionar alguém. Essas pessoas que muitas vezes apenas por admirarem a minha trajetória, me faziam indiretamente ter uma força em não desapontá-las, pois no fundo eu sabia que poderia ser a motivação que elas tanto precisavam para seguir em frente.

Por fim, mas não menos importante agradeço a oportunidade te ter tido grandes mestres no decorrer de todo o curso, principalmente ao meu orientador Benazzi por toda a paciência comigo, principalmente nessa reta final em me acolher como orientanda e me impulsionar para a construção de uma monografia de qualidade.

Estou muito feliz por concluir mais essa etapa.

"Se você pode sonhar, você pode fazer" Walt Disney

Eu sonhei e consegui! 


\section{Resumo}

Abreu, Vanessa. Análise das relações de consumo de bolsa de luxo da marca Michael Kors entre as mulheres das classes de renda A, B e C. Rio de Janeiro, 2016. 45 p. Trabalho de Conclusão de Curso - Departamento de Administração. Pontifícia Universidade Católica do Rio de Janeiro.

O presente trabalho tem como objetivo identificar quais fatores influenciam o consumo de bolsas de luxo pelas mulheres cariocas pertencentes às classes de renda $A, B$ e $C$ e o respectivo impacto do consumo entre as classes. A pesquisa foi de natureza exploratória com realização de três grupos de foco, um para cada classe de renda abordada. Esses grupos de foco visaram o reconhecimento desses fatores em sua fonte, auxiliando na análise do estudo. Os resultados visam o entendimento do consumo das classes de renda uma nas outras, e assim, elencar os principais fatores para consumo destas classes através de análises individuais e do comportamento do mercado.

Palavras- chave

Luxo, Classe de renda, Bolsa, Marca, Consumo

\section{Abstract}

Abreu, Vanessa. Analysis of relations of luxury purse consumption of the Michael Kors brand among women of the income classes A, B and C. Rio de Janeiro, 2016. 45 p. Trabalho de Conclusão de Curso - Departamento de Administração. Pontifícia Universidade Católica do Rio de Janeiro.

The present work has as goal to identify which factors have a influence on the luxury purse consumption by Rio de Janeiro local women whom belong to the income classes $\mathrm{A}, \mathrm{B}$ and $\mathrm{C}$ and the respective impact on consumption between classes. The research was of exploratory nature and accomplished with 3 focus groups, each one for every income class addressed. Those focus groups aimed the acknowledge of these factors on their sources, helping on study analysis. The result seeks to understand the consumption of these income classes each one to another, and, by doing so, enlist the main factors that leads to their consumption by those individual analysis and the market behavior.

\section{Key-words}

Luxury, Income classes, Purse, Brand, Consumption 


\section{Sumário}

1 O tema e o problema de estudo 1

1.1. Introdução ao tema e ao problema do estudo 1

1.2. Objetivo do estudo 3

1.3. Objetivos intermediários do estudo 3

1.4. Delimitação e foco do estudo 4

1.5. Justificativa e relevância do estudo 4

2 Revisão de literatura 6

2.1. Luxo, seu simbolismo e o significado do luxo para públicos de $\begin{array}{ll}\text { diferentes faixas de renda. } & 6\end{array}$

2.1.1. Definição de luxo e seu simbolismo 6

2.1.2. Luxo para diferentes classes de renda 8

2.2. Grupos de referência, identidade e autoimagem no consumo de luxo13

2.2.1. Grupos de referência 13

$\begin{array}{ll}\text { 2.2.2. Identidade e autoimagem no consumo de luxo } & 13\end{array}$

3 Métodos e procedimentos de coleta e de análise de dados do estudo 15

3.1. Etapas de coleta de dados 15

3.2. Fontes de informação selecionadas para coleta de dados no estudo15

3.3. Procedimentos e instrumentos de coleta de dados utilizados no $\begin{array}{ll}\text { estudo } & 16\end{array}$

3.4. Tratamento e análise dos dados 17

$\begin{array}{ll}\text { 3.5. Limitações do Estudo } & 18\end{array}$

4 Apresentação e análise dos resultados 19

4.1. Perfil das participantes dos grupos de foco 19

4.1.1. Grupo de foco 1 - Informantes de classe de renda C 19

4.1.2. Grupo de foco 2 - Classe de renda B 19

4.1.3. Grupo de foco 3 - Classe de renda A 20

4.2. Descrição e análise dos resultados dos grupos de foco 20 
4.2.1. Significados do Luxo 20

4.2.2. Marca de luxo 22

4.2.3. Disseminação do luxo e a marca Michael Kors 27

4.2.4. A bolsa e as interações no consumo 29

4.2.5. Representação 33

5 Conclusões e recomendações para novos estudos 38

5.1. Sugestões e recomendações para novos estudos 39

6 Referências Bibliográficas $\quad 40$

$\begin{array}{ll}\text { Anexo } 1 & 42\end{array}$

$\begin{array}{ll}\text { Anexo } 2 & 44\end{array}$

\section{Lista de figuras}

Figura 1: Variáveis do sistema de ponto ........................................................ 9

Figura 2: Grau de instrução do chefe de família e acesso a serviços públicos .... 9

Figura 3: Cortes de pontos do Critério Brasil ................................................. 10

Figura 4: Estimativa de renda ABEP .................................................. 10

Figura 5: Mulher 1 usando bolsa Michael Kors ............................................. 34

Figura 6: Mulher 2 usando bolsa Michael Kors ............................................... 36

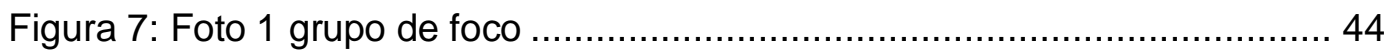

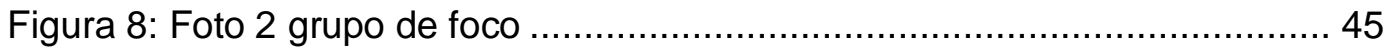




\section{Lista de Tabelas}

Tabela 1: Dados das participantes do grupo de foco 1 .................................. 19

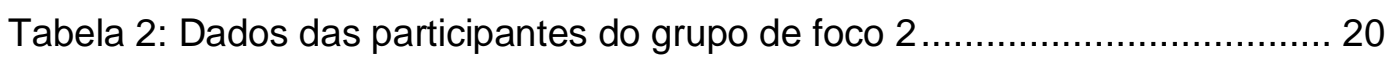

Tabela 3: Dados das participantes do grupo de foco 3 .................................. 20

Tabela 4: Comparativo Idade x utilização marca Michael Kors......................... 26 


\section{0 tema e o problema de estudo}

Esse capítulo volta-se à apresentação do tema que se pretende desenvolver e do problema de estudo.

Assim, apresenta-se o problema que suscitou a proposta de investigação e respectivos objetivos de pesquisa. Na sequência, são indicadas as suposições e as hipóteses do estudo e se informa a relevância e justificativa do estudo e a delimitação e foco do estudo.

\subsection{Introdução ao tema e ao problema do estudo}

Segundo Lipovetsky e Roux (2012), o luxo aparece como uma esfera mais em conivência com o feminino do que com o masculino, mais vinculada ao universo dos agrados femininos do que ao dos homens. Joias, moda, acessórios, casacos de pele, lingeries, perfumes, produtos de beleza e de cuidados, decoração da casa, artes de mesa, são setores que dominam o consumo feminino no mercado de luxo. Dessa forma, no quesito moda e acessórios onde bolsa está inserida, trata-se muito mais de um consumo realizado por mulheres do que por homens, por isto elas serão o objeto deste estudo. Consumidoras das classes de renda $A, B$ e $C$ relacionam-se no consumo desse mercado.

O consumo de bens de luxo traz consigo significados e valores que apoiam a criação de uma identidade e acabam por revelar quem são as pessoas que os consomem. Esse consumo é influenciado por fatores de ordem social, cultural, psicológico e pessoal (DINIZ, 2013). Ao analisarmos as classes do topo da pirâmide, o consumo do luxo é voltado para manter o status social e familiar, a exclusividade e a qualidade percebida nos produtos, enquanto que as classes mais populares estão interessadas na experiência de aspiração social ao utilizar produtos característicos de classes mais abastadas (PARENTE; BARKI e GEARGEOURA, 2008).

Segundo Lipovetsky e Roux (2012) em 1980 começa o processo de democratização do luxo, onde as classes de renda mais baixas têm acesso a produtos destinados as classes de renda superiores às deles. Ocorrendo, dessa forma, um processo de diversificação no consumo de luxo. 
Esse fenômeno se prolongou com a melhora econômica alcançada pelos países emergentes nos últimos anos, no qual o Brasil está inserido. Como consequência de uma economia mais forte as pessoas possuíam um poder de compra maior e acesso facilitado a linhas de crédito, o que favoreceu o consumo (MARCELA KAWAUTI 2015). Esse contexto acarretou um aumento expressivo na demanda por itens de luxo nestes países, principalmente pela classe de renda C, conforme estudo feito pelo Serviço de Proteção ao Crédito (SPC Brasil).

Considerando o atual período de recessão na economia brasileira e de acordo com estudo realizado pela Associação Brasileira das Empresas de Luxo (Abrael), o segmento de luxo cresceu de $11 \%$ a $13 \%$ no ano de 2015 , conforme os dados de um mercado que possui como seu principal público alvo pessoas da classe de renda A (FERREIRINHA, 2016). Mostrando que as consumidoras de maior poder aquisitivo sofrem menos com os efeitos da inflação e deterioração da renda, continuando assim a consumir.

Dessa forma, coexiste de acordo com Lipovetsky e Roux (2012) duas formas no mercado de luxo: uma intermediária e outra acessível. No qual as marcas de luxo tem que conciliar o consumo da elite com consumo das classes mais populares. A elite compra para manter sua posição social e se diferenciar do consumo das massas, enquanto que as classes mais populares adquirem bens de luxo com intuito de terem reconhecimento social. Assim, as marcas devem encontrar o equilíbrio entre a disseminação e a banalização do luxo. (LIPOVETSKY e ROUX, 2012).

Conforme Strehlau (2008) a decisão de consumir uma marca não se dá apenas pelas características físicas de seus produtos, mas também pela personalidade, potencial simbólico e valores que a marca representa.

A marca Michael Kors ficou muito conhecida junto ao público feminino brasileiro, especialmente as de classe de renda $C$, através do uso de sua bolsa pela personagem Carminha, protagonizada pela atriz Adriana Esteves em Avenida Brasil, novela de horário nobre, transmitida em 2012 pela TV Globo, a qual teve grande audiência por parte dessa classe de renda, conforme (AMANDA BRITTO, 2014). O sucesso alcançado pela novela, conforme dados divulgados pela Veja Rio e G1 intensificou o consumo da marca, sendo um dos fatores considerados para decisão da empresa de abertura da atual filial no shopping Village Mall (LOUISE PERES, 2012).

A bolsa tem um significado diferenciado para o público feminino, de acordo com Johson (2007) a bolsa feminina carrega uma carga erótica e ousada devido 
ao seu exterior admirável e seu interior extremamente íntimo - o último local secreto de uma mulher -, e de sua linguagem territorial e ligada à possessão. Ainda, esses objetos podem ser usados em cerimônias formais, festas, encontros entre amigos, no trabalho entre outras ocasiões (JUGGESSUR, 2011).

A bolsa ideal não é simplesmente um produto e sim extensão da identidade da mulher que a usa como uma forma de realização pessoal, pois transforma o objeto que em essência serviria para carregar itens e acessórios em um campo dos sonhos, do desejo e da libertação do cotidiano, é o objeto que resiste às alterações do corpo e do tempo e leva as mulheres às vidas que gostariam de ter, podendo transformar uma plebeia em princesa (JOHNSON, 2007).

Dessa forma, cabe o seguinte questionamento: Qual a relação no consumo de bolsa de luxo da marca Michael Kors entre as mulheres das classes de renda $A, B$ e $C$ e quais são os fatores determinantes declarados por elas que justificam esse consumo?

\subsection{Objetivo do estudo}

Este trabalho tem como objetivo avaliar a relação no consumo de bolsas da marca Michael Kors entre as mulheres das classes de renda $A, B$ e $C$, tendo em vista que, embora este produto seja considerado um bem de luxo e é destinado para mulheres de classes de renda do topo da pirâmide, elas também são compradas e usadas por mulheres de classes de renda mais populares.

Portanto este trabalho pretende contribuir para que a partir dessas análises sejam identificadas quais as consequências que o ato de consumir uma bolsa da marca Michael Kors por classes de renda diferentes pode ocasionar uma nas outras. Serão analisadas as interferências no consumo da classe de renda A, B e C separadamente, chegando assim à conclusão do objetivo do estudo, de identificar quais são esses fatores, tendo como base os dados coletados da pesquisa entre os grupos estudados.

\subsection{Objetivos intermediários do estudo}

Para se atingir o objetivo final proposto esse estudo prevê, como objetivos intermediários a serem alcançados:

$\checkmark$ Identificar as características das classes de renda, utilizando de questões externas, como: renda, idade, cultura, levando em consideração também fatores internos, como: seus anseios, motivações, experiências pessoais e valores. 
$\checkmark$ Investigar os pontos de intercessão de uma classe de renda com a outra chegando à conclusão do que levam essas mulheres a adquirem o mesmo item, sendo de classes de renda diferentes.

$\checkmark$ Debater até que ponto o consumo de uma classe de renda pode impactar no consumo na outra.

$\checkmark$ Relacionar qual é o valor da marca Michael Kors para cada classe de renda.

\subsection{Delimitação e foco do estudo}

Este estudo volta-se mais especificamente para abordar as razões que levam as mulheres cariocas a adquirir bolsas de luxo da marca Michael Kors sob o ponto de vista específico das classes de renda A, B e C. Tal ângulo de análise se mostra interessante e importante por que impactam no consumo uma das outras.

O foco do estudo será levantar quais fatores fazem com que essas mulheres comprem uma bolsa dessa marca. Como elas veem o consumo e o uso do mesmo item por outras mulheres das demais classes estudadas chegando ao ponto de identificar se isso de fato as afeta. O que consideram importante para compra, identificando suas autoimagens e as imagens que essas mulheres fazem das outras consumidoras de classes de renda diferentes da sua e se isso afeta a recompra da marca. Será também questionado sobre o valor monetário empregado para compra desse item, o qual muitas vezes passa da realidade econômico-financeira de muitas. O horizonte temporal do estudo em questão será durante o segundo semestre de 2016.

Embora relevante, não se pretende tratar da questão de compra de outras marcas de luxo já que tal perspectiva não chegaria a conclusões precisas sobre o tema.

\subsection{Justificativa e relevância do estudo}

O estudo analisará um mercado rentável para muitas empresas do segmento de luxo, que é o brasileiro, auxiliando na identificação do comportamento de compra desse consumidor, seus anseios, suas expectativas através de uma importante figura que é a feminina. Essas informações servirão como base para estruturação de estratégias de marketing e uma maior assertividade na comunicação e no alcance da marca, auxiliando assim a delimitar que público ela pretende impactar. 
Além de levantar a questão da ascensão cultural e até mesmo econômica de classes que até pouco tempo não tinham acesso a luxo, entendendo essa migração de comportamento de consumo e levando para empresas, auxiliando também como artigo acadêmico, servindo para ambos como estudo sobre os hábitos de consumo da baixa renda e sua influência no hábito de consumo nas rendas mais elevadas.

Para a sociedade, servirá como auxílio no entendimento do luxo como algo histórico e mistificado a cultura da população brasileira, as formas que ele caracteriza as pessoas e sua importância nas relações sociais. 


\section{Revisão de literatura}

Neste capítulo são apresentados e discutidos aspectos conceituais e estudos relacionados ao tema e estudo em investigação e que servirão de base para a análise realizada.

Esta seção está dividida em duas partes e abordam, respectivamente, a questão do luxo, seu simbolismo e o significado do luxo para públicos de diferentes faixas de renda, grupos de referência, identidade e autoimagem no consumo de luxo objetivando assim a contextualização com o problema de estudo.

\subsection{Luxo, seu simbolismo e o significado do luxo para públicos de diferentes faixas de renda.}

Cada indivíduo possui um desejo, o qual se manifesta e se forma através da junção de vários fatores internos e externos, como: o social, o cultural e o pessoal e o luxo vai de carona nesses fatores, formando o seu significado para cada individuo.

Hoje vemos nos países emergentes, nos quais o Brasil está incluído, um mercado bastante rentável para o consumo do luxo, porém engana-se quem acredita que são consumidores passivos, os quais entenderão e repassarão a simbologia que a marca impõe. De acordo com Strehlau (2008), esses consumidores alteram o significado das marcas ao comprá-las e utilizá-las.

\subsubsection{Definição de luxo e seu simbolismo}

Definir luxo é um desafio, não há um acordo universal sobre a sua definição. Mas sabe-se que luxo começou antes mesmo de sua história nascer (LIPOVETSKY e ROUX, 2012). Segundo Strehlau (2008) o conceito de luxo tem natureza dinâmica e se materializa em um objeto, marca ou serviço. Tem como referência aquilo que é raro, exclusivo ou caro, restrito, gerador de distinção social, tradição e qualidade, contrapondo à necessidade, fornecendo destaque para aqueles que o consome. Seus produtos, resultado de sua teoria e conceito se resumem em: alta qualidade aliada a uma marca forte, preço premium, comunicação seletiva ressaltando a imagem, distribuição seletiva ou exclusiva. Trata-se também de um adjetivo associado a um substantivo com o intuito de 
qualificá-lo, distanciando da ideia do que seria comum ou normal, como exemplo a autora utiliza de uma propaganda que oferece férias de luxo com ônibus fretado, atribuindo as férias um sentido de especial, luxo sendo diferente do que poderia se declarar como férias comuns.

O significado do luxo mudou ao longo da história, principalmente em decorrência da evolução material, transformando o que era luxo de uma determinada época em necessidade para outra (D'ANGELO, 2006). O luxo passou de uma lógica artesanal e familiar para uma lógica industrial e financeira. De inicio esse consumo industrial se relacionava ao sentido de acumulação e ostentação. Hoje, há um deslocamento do significado e das motivações do consumo de luxo para o campo dos sentidos, dessa forma, o consumo do luxo está muito mais voltado às experiências, às emoções e ao prazer. (LIPOVETSKY e ROUX, 2012).

Logo o termo luxo ficou dividido entre tradicional e o contemporâneo, também chamado de novo luxo. O primeiro é mais materialista, conforme conceito explicito no início deste tópico e o segundo carrega em seu significado outras variáveis, onde os indivíduos têm um referencial próprio sobre o conceito do luxo. Conforme Solomon (2011) está ficando cada vez mais difícil associar claramente algumas marcas a uma classe específica. Isto ocorre porque muito luxo "de preço acessível" está ao alcance de consumidores que não podiam acessá-las no passado, estas são algumas das consequências do então denominado novo luxo, processo intensificado através da democratização do luxo.

O novo luxo, conforme Diniz (2012) seria mais o pertencer do que propriamente o ter. Antes, o rico para se diferenciar comprava joias, viviam em mansões, hoje preferem se diferenciar vivendo experiências ou até mesmo sendo filantrópico, tendo seu nome ligado a uma fundação e não necessariamente em despertar inveja no outro por uso de determinado bem material, seria mais uma visão narcisista, um deleite sobre si mesmo (LIPOVETSKU e ROUX, 2012).

Os pós-modernos reconhecem o amplo papel do simbólico no desenvolvimento de construção de necessidades: o modo como a cultura dá significado e uso aos objetos organiza e estrutura as necessidades (FIRAT ET AL. 1995). Abundantes em significados e simbologia, influenciados por valores culturais e individuais, produtos de luxo são desejados mais por suas características intangíveis do que por sua função utilitária (D’ANGELO 2006). 
Essa definição aproxima-se mais a que é utilizada hoje pelas marcas, o que aconteceu com o passar do tempo foi uma massificação do que antes era exclusivo e outros valores estão sendo utilizados para não perderem o vínculo da marca e o luxo. Para que, dessa forma, a disseminação das marcas impacte menos e seja mais bem trabalhado para manutenção da sua identidade. Segundo Diniz (2012) seria algo que estamos mais longe de alcançar como ter tempo com a família, ter tempo ao ócio ter a oportunidade de fazer viagens inesquecíveis com amigos, esses fatores são os atuais valores reconhecidos pelo público de alto luxo como luxo.

O que vemos atualmente com a democratização é a expansão da mentalidade consumista, onde objetos têm função e valor associado a simbolismo, o que une o real ao imaginário. As pessoas não compram simplesmente uma bolsa, elas compram o objeto bolsa mais uma série de significados que possuir aquela bolsa representa para ela. O consumo do luxo hoje utiliza de fatores psicológicos, deixa de satisfazer apenas as necessidades básicas, dando significado emocional. O luxo é importante neste trabalho, pois é através dele que as pessoas enxergam esse lado imaginário e da realização através do consumo, no caso mais específico das mulheres torna real seus desejos e sonhos.

\subsubsection{Luxo para diferentes classes de renda}

Segundo Solomon (2011) utiliza-se a expressão classe social mais genericamente para descrever a classificação global das pessoas na sociedade, pois as pessoas tendem naturalmente a se estratificar de forma a interagir mais com seus semelhantes em termos de posição social, política, estilo de vida ou quaisquer outros fatores que tenham em comum dentro de sua comunidade. Sendo assim, os profissionais de marketing visam estudar essas classes para atendê-las de forma adequada ao que cada uma delas valoriza e acredita.

Ainda conforme Solomon (2011), para classificar as classes é necessário considerar fatores como prestígio ocupacional ou profissão, renda, bens adquiridos com a renda do indivíduo, educação e visão de mundo.

Em visão disto será utilizado neste trabalho critério da Associação Brasileira de Empresas de Pesquisa (ABEP) para distinguir as classes de renda abordadas.

Conforme critério ABEP disponibilizado em 2016 na sua página oficial tem como foco segmentar as classes de acordo com as características domiciliares que cada indivíduo possui dentro de sua residência, sua posição na família e seu 
grau de escolaridade e seu acesso a serviços públicos. Sendo assim, a renda não é mais medida pelo salário per capita.

Entende-se por características domiciliares todos os bens, cômodos e mão de obra que a pessoa possua em sua residência que tragam conforto e qualidade de vida para si e sua família, tais como geladeiras, máquinas de lavar, quantidade de banheiros, quantidade de empregadas, entre outros. Aqui a pontuação será feita de acordo com quantidade de cada item que o compõe.

Por grau de escolaridade e posição familiar, o critério aborda até que grau de ensino o cidadão avançou academicamente e se o mesmo é o responsável pelo sustento familiar ou por maior parte dela.

É também considerado o acesso a serviços públicos, e neste atributo são considerados os serviços básicos garantidos por lei como água encanada para a própria estrutura domiciliar e se a rua aonde o indivíduo reside é pavimentada.

Este critério atribui pontos pra cada uma das características abordadas, e a soma desses pontos que irá definir a qual estrato social de renda o indivíduo enquadra conforme mostram os quadros abaixo:

\begin{tabular}{|l|l|l|l|l|l|}
\hline & & \multicolumn{5}{|c|}{ Quantidade } & & \\
\hline & 0 & 1 & 2 & 3 & 4 ou + \\
\hline Banheiros & 0 & 3 & 7 & 10 & 14 \\
\hline Empregados domésticos & 0 & 3 & 7 & 10 & 13 \\
\hline Automóveis & 0 & 3 & 5 & 8 & 11 \\
\hline Microcomputador & 0 & 3 & 6 & 8 & 11 \\
\hline Lava louca & 0 & 3 & 6 & 6 & 6 \\
\hline Geladeira & 0 & 2 & 3 & 5 & 5 \\
\hline Freezer & 0 & 2 & 4 & 6 & 6 \\
\hline Lava roupa & 0 & 2 & 4 & 6 & 6 \\
\hline DVD & 0 & 1 & 3 & 4 & 6 \\
\hline Micro-ondas & 0 & 2 & 4 & 4 & 4 \\
\hline Motocicleta & 0 & 1 & 3 & 3 & 3 \\
\hline Secadora roupa & 0 & 2 & 2 & 2 & 2 \\
\hline
\end{tabular}

Figura 1: Variáveis do sistema de ponto

(Fonte: ABEP, 2016)

\begin{tabular}{|c|c|}
\hline \multicolumn{2}{|l|}{ Escolaridade da pessoa de referência } \\
\hline Analfabeto / Fundamental I incompleto & 0 \\
\hline Fundamental I completo / Fundamental II incompleto & 1 \\
\hline Fundamental II completo / Médio incompleto & 2 \\
\hline Médio completo / Superior incompleto & 4 \\
\hline Superior completo & 7 \\
\hline \multicolumn{2}{|l|}{ Serviços públicos } \\
\hline Não & Sim \\
\hline Água encanada & 4 \\
\hline Rua pavimentada & 2 \\
\hline
\end{tabular}

Figura 2: Grau de instrução do chefe de família e acesso a serviços públicos (Fonte: ABEP, 2016) 


\begin{tabular}{|cc|}
\hline Classe & Pontos \\
\hline A & $45-100$ \\
\hline B1 & $38-44$ \\
\hline B2 & $29-37$ \\
\hline C1 & $23-28$ \\
\hline C2 & $17-22$ \\
\hline D-E & $0-16$ \\
\hline
\end{tabular}

Figura 3: Cortes de pontos do Critério Brasil

(Fonte: ABEP, 2016)

\begin{tabular}{|cc|}
\hline $\begin{array}{c}\text { Estrato Sócio } \\
\text { Econômico }\end{array}$ & $\begin{array}{c}\text { Renda média } \\
\text { Domiciliar }\end{array}$ \\
\hline A & $20.272,56$ \\
\hline B1 & $8.695,88$ \\
\hline B2 & $4.427,36$ \\
\hline C1 & $2.409,01$ \\
\hline C2 & $1.446,24$ \\
\hline D - E & 639,78 \\
\hline TOTAL & $\mathbf{2 . 8 7 6 , 0 5}$ \\
\hline
\end{tabular}

Figura 4: Estimativa de renda ABEP

(Fonte: ABEP, 2016)

Para ser preciso na coleta das informações para classificar as classes de renda a própria $A B E P$ fornece questionário objetivo que visa à adequada coleta de cada tópico, conforme a imagem abaixo: 


\section{INSTRUÇÃO: Todos os itens devem ser perguntados pelo entrevistador e respondidos pelo entrevistado. \\ Vamos começar? No domicílio tem (LEIA CADA ITEM)}

\begin{tabular}{|c|c|c|c|c|c|}
\hline ITENS DE CONFORTO & $\begin{array}{l}\text { NÃO } \\
\text { POSSUI }\end{array}$ & 1 & 2 & 3 & $4+$ \\
\hline \multicolumn{6}{|l|}{$\begin{array}{l}\text { Quantidade de automóveis de passeio exclusivamente para } \\
\text { uso particular }\end{array}$} \\
\hline \multicolumn{6}{|l|}{$\begin{array}{l}\text { Quantidade de empregados mensalistas, considerando apenas } \\
\text { os que trabalham pelo menos cinco dias por semana }\end{array}$} \\
\hline \multicolumn{6}{|l|}{ Quantidade de máquinas de lavar roupa, excluindo tanquinho } \\
\hline \multicolumn{6}{|l|}{ Quantidade de banheiros } \\
\hline \multicolumn{6}{|l|}{$\begin{array}{l}\text { DVD, incluindo qualquer dispositivo que leia DVD e desconsiderando } \\
\text { DVD de automóvel }\end{array}$} \\
\hline \multicolumn{6}{|l|}{ Quantidade de geladeiras } \\
\hline \multicolumn{6}{|l|}{ Quantidade de freezers independentes ou parte da geladeira duplex } \\
\hline \multicolumn{6}{|l|}{$\begin{array}{l}\text { Quantidade de microcomputadores, considerando computadores } \\
\text { de mesa, laptops, notebooks e netbooks e desconsiderando tablets, } \\
\text { palms ou smartphones }\end{array}$} \\
\hline \multicolumn{6}{|l|}{ Quantidade de lavadora de louças } \\
\hline \multicolumn{6}{|l|}{ Quantidade de fornos de micro-ondas } \\
\hline \multicolumn{6}{|l|}{$\begin{array}{l}\text { Quantidade de motocicletas, desconsiderando as } \\
\text { usadas exclusivamente para uso profissional }\end{array}$} \\
\hline $\begin{array}{l}\text { Quantidade de máquinas secadoras de roupas, considerando lava } \\
\text { e seca }\end{array}$ & & & & & \\
\hline
\end{tabular}

A água utilizada neste domicílio é proveniente de?

\begin{tabular}{|c|l|}
\hline \multicolumn{2}{|l|}{ A água utilizada neste domicilio é proveniente de? } \\
\hline 1 & Rede geral de distribuição \\
\hline 2 & Poço ou nascente \\
\hline 3 & Outro meio \\
\hline
\end{tabular}

Considerando o trecho da rua do seu domicilio, você diria que a rua é:

\begin{tabular}{|c|l|}
\hline 1 & Asfaltada/Pavimentada \\
\hline 2 & Terra/Cascalho \\
\hline
\end{tabular}

Qual é o grau de instrução do chefe da família? Considere como chefe da família a pessoa que contribui com a maior parte da renda do domicílio.

\begin{tabular}{|l|l|}
\hline \multicolumn{1}{|c|}{ Nomenclatura atual } & \multicolumn{1}{c|}{ Nomenclatura anterior } \\
\hline Analfabeto / Fundamental I incompleto & Analfabeto/Primário Incompleto \\
\hline $\begin{array}{l}\text { Fundamental I completo / Fundamental II } \\
\text { incompleto }\end{array}$ & $\begin{array}{l}\text { Primário Completo/Ginásio } \\
\text { Incompleto }\end{array}$ \\
\hline $\begin{array}{l}\text { Fundamental completo/Médio } \\
\text { incompleto }\end{array}$ & $\begin{array}{l}\text { Ginásio Completo/Colegial } \\
\text { Incompleto }\end{array}$ \\
\hline Médio completo/Superior incompleto & $\begin{array}{l}\text { Colegial Completo/Superior } \\
\text { Incompleto }\end{array}$ \\
\hline Superior completo & Superior Completo \\
\hline
\end{tabular}

Figure 1: Questionário ABEP de classificação de renda (Fonte: ABEP, 2016) 
De acordo com Strehlau (2008) o conceito de luxo existe desde a antiguidade. Todavia, o que era luxo no século XIX não pode ser mais considerado como tal. Isto porque, apesar do conceito ser estável - tanto que ainda existe -, os bens nos quais se manifesta são mutantes. O luxo muda por vários fatores, seja por contexto histórico, cultura no meio que ele se insere até as particularidades de cada individuo. Dessa forma a renda se torna um fator importante na concepção do conceito de luxo e serão apresentadas as principais interpretações e como elas variam de acordo com as classes estudas.

De acordo com estudo realizado com 945 respondentes, maiores de 18 anos, brasileiros, das classes de renda A, B e C pela Sociedade de Proteção ao Crédito (SPC Brasil) e Meu Bolso Feliz, publicada em abril de 2015, as pessoas consideram que uma vida de luxo está associada a poder gastar o que bem quiser, onde e quando quiser. Essa visão é compartilhada por $39 \%$ na classe A e $52 \%$ nas classes $B$ e $C$, percebe-se com isso que as classes mais populares veem o luxo como sendo o consumo sem restrição, poder gastar sem fazer cortes no orçamento ou contrair dívidas. $47 \%$ do total de respondentes disseram que luxo é poder viajar sempre que se tem vontade, essa visão é compartilhada por $63 \%$ na classe $A, 54 \%$ na classe $B$ e $42 \%$ na classe $C$, vemos com isso que as classes de renda do topo da pirâmide estão mais interessadas na experiência, no vivenciar e não no adquirir. Essa afirmativa é reforçada no estudo em outras questões como ter tempo para curtir com amigos e familiares, onde $39 \%$ da classe A considera luxo, contra $30 \%$ na classe C e $28 \%$ na classe B. Portanto a classe A considera que quem pode passar mais tempo com essas pessoas fornecem um luxo a si mesmas, mais uma vez a experiência ganha lugar do bem em si. 17\% dos respondentes associam luxo à qualidade superior quando comparados com outros itens, desses $25 \%$ são da classe $\mathrm{A}, 18 \%$ da classe $B$ e $16 \%$ na classe $C$, logo qualidade é um fator mais importantes para a classe A no que se refere a consumo de luxo.

A ideia de democratizar o luxo é mais aceita pelas classes mais populares $76 \%$ na classe C, $75 \%$ na classe B e $68 \%$ na classe A. $75 \%$ do grupo pesquisado concorda que todos deveriam poder acessar um produto luxo pelo menos uma vez. No grupo pesquisado $32 \%$ demostrou que gastar com produtos de luxo é não ter noção do dinheiro, 34\% foram classe C, contra $23 \%$ na classe $A$, reforçando a ideia de que a classe $A$ tem menor sensibilidade ao fator preço, possivelmente por sua condição financeira.

No que concerne à aparição da marca de luxo nos itens comprados ela se mostrou menos importante na classe A, onde apenas $29 \%$ gostam quando a 
marca está visível contra $45 \%$ da classe C. Isto remete a questão do consumo pela ostentação em demonstrar para os outros uma ideia de status, mais compartilhada pelas classes mais populares, nesse caso em específico na classe de renda $C$. Isso é explicado, pois se trata de uma classe que ainda está no primeiro estágio de consumo do luxo, enquanto que para as classes $A$ e $B$ que são consumidores do luxo a mais tempo, ele remete o significado de vivência e experiência, não é mais apenas o ter.

\subsection{Grupos de referência, identidade e autoimagem no consumo de luxo}

Nesta seção será abordada a importância dos grupos de referência, bem como os conceitos de identidade e autoimagem de marketing aplicado ao consumo de luxo.

\subsubsection{Grupos de referência}

De acordo com Solomon (2011) os humanos são animais sociais, os quais precisam se sentir pertencentes e isso muitos vezes se dá quando nos aproximamos do que é feito por grupos dominantes, o que nos faz sermos aceitos. Esses grupos podem ser reais ou imaginários com poder de influenciar determinado comportamento a ser seguido/almejado, eles são importantes, pois influenciam através de várias faixas de poder.

O mais aplicável a esse trabalho seria o poder referente que segundo Solomon (2011) é quando uma pessoa admira e tenta imitar as qualidades através do comportamento de alguém ou de um grupo, como por exemplo, escolhas de roupas, marcas, nesse contexto tentando agradar a alguém ou algo.

Os grupos de referências são muito importantes neste trabalho, pois as classes dominantes A e B são por muitas vezes copiadas pelas classes mais populares com o intuito de se assemelhar a um grupo que elas admiram.

\subsubsection{Identidade e autoimagem no consumo de luxo}

Conforme Lorda (2011), a identidade passa pela ótica do psicológico e individual, e também pela ótica social e suas inúmeras interações. A forma como uma pessoa age, suas decisões e seus caminhos trilhados são elementos que influenciam em sua identidade e também em seu 'pertencimento', os quais não são assegurados para a vida toda, e sim negociáveis e revogáveis (BAUMAN, 2005). Na atual sociedade do capitalismo tardio, assim nomeada por Venturelli (2010), a individualização é exaltada, o que afeta a criação das identidades. Isto é percebido pelas marcas, que possuem dificuldade na comunicação assertiva 
de um público alvo, muito disso vem sendo solucionado através da personalização oferecida pelas empresas para distinguir e dar exclusividade frente a um consumo de massas.

Segundo Kotler e Keller (2012) identidade são as características do comportamento de compra, conjuntos de traços psicológicos que traduzem a identidade de um consumidor e/ou marca. De acordo com Strehlau (2008) identidade de uma marca são os elementos e o que ela quer significar, os valores que ela quer passar para quem utiliza, possuem um papel simbólico na decisão de compra.

A autoimagem pode ser real, ideal ou de acordo e para outros. De acordo com Kotler; Keller (2012) a autoimagem real seria de como a pessoa se vê, a ideal de como ela gostaria de se ver e a de acordo com os outros seriam como ela pensa que os outros a veem. Esse encontro dos desejos internos ao que a sociedade julga como importante é o que faz as pessoas se motivarem a consumirem luxo, a busca da autoimagem ideal o se espelhar para parecer ou ser melhor.

Há pessoas que sentem necessidade de passar uma imagem social de bem-sucedidas, ricas, ou aspiram ser vistas como atraentes, sofisticadas e, por isso, como constatam Blackwell et al (2005), determinadas empresas considera isso para reforçar a noção de que seus produtos ligam elas a tais imagens, influenciando-as a comprarem pelo desejo de exibir a circunstância que almejam. Ao utilizar o luxo, por exemplo, o consumidor passa uma imagem de pertencimento a um nível superior na hierarquia social, afirma Barth (1996), atribuindo uma conotação de que a pessoa faz parte de um grupo distinto numa grande sociedade de massa.

A identidade e autoimagem são importantes no consumo do luxo feminino, pois remetem a ideia e a análise da própria identidade com a imagem de como elas gostariam de ser enxergadas pelas pessoas. Através das identidades fornecidas pelas marcas elas conseguem muitas vezes encontrar a distinção social que elas procuram. 


\section{Métodos e procedimentos de coleta e de análise de dados do estudo}

Este capítulo pretende informar sobre as diversas decisões a cerca da forma como este estudo foi realizado.

Está dividido em cinco seções que informam, respectivamente, sobre as etapas de coleta de dados do estudo realizado, sobre as fontes de informação selecionadas para coleta de informações neste estudo. Na sequência, informase sobre os processos e instrumentos de coleta de dados realizados em cada etapa, com respectivas justificativas, sobre as formas escolhidas para tratar e analisar os dados coletados e, por fim, sobre as possíveis repercussões que as decisões sobre como realizar o estudo impuseram aos resultados assim obtidos.

\subsection{Etapas de coleta de dados}

Este trabalho possui duas etapas de coleta de dados no campo.

A primeira etapa consistiu de uma pesquisa observacional em uma filial da marca Michael Kors, situada no Village Mall na cidade do Rio de Janeiro para vivenciar a experiência de compra das consumidoras, bem como entender melhor o público que a consome. Dessa forma amplificando o entendimento do tema em questão para posterior confecção do relatório e aprofundamento do objeto do estudo, na etapa seguinte: o grupo de foco.

A segunda etapa foi composta por uma aplicação de pesquisa qualitativa, através da técnica de grupo de foco. Essa técnica permite um estudo mais aprofundado dentro das classes estudadas, visando responder à pergunta problema do tema.

A justificativa para realizar esse dois tipos de pesquisa é proporcionar uma visão geral, sendo posteriormente aproximada sobre o tema do estudo, já que se trata de um tema que tem por trás vários fatores envolvidos.

\subsection{Fontes de informação selecionadas para coleta de dados no estudo}

Foram utilizadas fontes já existentes sobre o tema, como estudos, artigos acadêmicos, livros e matérias na internet de pessoas conhecedoras do mercado, um bom exemplo é o empresário Carlos Ferreirinha, principal formador de opinião e especialista sobre a inteligência da Gestão do Luxo e Premium na 
América Latina, onde atuou também como diretor no grupo LVMH (Roland Herlory, 2016). O site da associação brasileira das empresas de luxo (ABRAEL), bem como tantos outros com notícias e opiniões recentes foram considerados.

$\mathrm{Na}$ primeira etapa buscaram-se informações junto aos compradores da loja Michael Kors situada no Village Mall, Barra da Tijuca. A escolha do local para se aplicar a pesquisa observacional se deve por ser a principal loja de venda do produto ora estudado dentro do estado do Rio de Janeiro, atendendo assim grande parte das consumidoras cariocas que compram o produto no Brasil. Foi considera essa forma de pesquisa, tendo em vista que é uma oportunidade de contato real e direto com o consumidor desse mercado que opta e tem acesso a comprar diretamente da fonte e poderia enriquecer aos temas abordados nos grupos de foco.

Para a segunda etapa foram realizados três grupos de foco escolhidos por conveniência, por ser pessoas de fácil acesso e da rede de contatos do autor. Essas pessoas foram alcançadas através de pedidos informais a amigos e convite realizados pelos amigos a demais possíveis candidatas, colegas de trabalho, colegas da faculdade, para se ter uma quantidade considerável de mulheres para posteriormente agrupá-las de acordo com a renda no respectivo grupo de foco pertencente a sua classe. Com isso criando grupos de foco homogêneo em participantes e coesos com a classificação ABEP para não prejudicar os resultados.

Os dados foram coletados através de roteiro estruturado para aplicação de grupo de foco. Foram realizados três grupos de foco com participação de 3 a 6 mulheres. Os fatores levados em consideração para que a mulher estivesse apta a participar do grupo de foco, foram: conhecer marca Michael Kors, ser participante de uma das classes de renda do estudo, de acordo com a classificação da ABEP e ser residente do estado do Rio de Janeiro.

\subsection{Procedimentos e instrumentos de coleta de dados utilizados no estudo}

Na primeira etapa a coleta ocorreu por meio da técnica de grupo de foco. As questões abordadas no roteiro foram produzidas a partir das leituras de textos, livros, artigos acadêmicos e noticias do mercado aliado ao que foi visto na visita realizada a loja Michael Kors. O grupo de foco foi realizado foi realizado em três datas distintas, levando-se em consideração o tempo para realização do mesmo e a disponibilidade das entrevistadas. O primeiro grupo foi composto por mulheres da classe de renda $A$, o segundo grupo composto por mulheres da 
classe de renda $\mathrm{B}$ e o terceiro e último grupo composto por mulheres da classe de renda $\mathrm{C}$, conforme respostas e pontuação dadas de acordo com aplicação do questionário ABEP (Anexo 1). Um roteiro foi utilizado, pois era a melhor forma de organizar as ideias e direcionar a conversa ao foco do estudo, resultando em respostas para o tema, evitando a dispersão.

Essas mulheres foram reunidas em locais e horários diferentes tendo em vista a disponibilidade de cada uma, encontrando um local e horário em comum para agenda de ambas para que pudessem estar presentes nos respectivos grupos de foco. O primeiro grupo de foco realizado foi de mulheres pertencentes à classe de renda $\mathrm{C}$. A conversa aconteceu numa sala de reunião no local de trabalho do autor no centro comercial do Rio de Janeiro. As entrevistadas foram organizadas em volta de uma mesa onde todas podiam se ver, inclusive a mediadora que é autora do presente trabalho. Foi solicitada pela mediadora autorização de gravação e uso de imagem, caso viesse a ter necessidade. $\mathrm{Na}$ mesa continham bebida e sanduiches a disposição das entrevistadas. A mediadora levou seu laptop e como a sala possuía recurso de retroprojetor ele foi utilizado em determinado momento de análise para exibição de duas imagens para levantamento de questões sobre determinado tema. As demais perguntas escritas foram faladas pela mediadora, onde se buscou ser o mais clara possível para as entrevistadas entenderem o teor das perguntas. As entrevistadas discorriam entre elas e com a medidora em diversos momentos, o que deixou bastante rico o teor da conversa.

O segundo grupo de foco foi realizado no IAG, na PUC Rio com mulheres pertencentes à classe de renda $B$, em condições parecidas ao do primeiro de foco, excluindo a utilização de retroprojetor. O terceiro grupo de foco foi realizado em sala comercial no shopping Leblon, por ser o ambiente de trabalho das mulheres de classe de renda A, participantes do grupo de foco, em condições também parecidas com o primeiro grupo de foco.

$O$ roteiro do grupo de foco e as respectivas imagens utilizadas foram tratadas através de técnica projetista, onde pediu-se para que as entrevistadas associassem um animal às fotos apresentadas conforme roteiro que está disponível no anexo 2 do presente trabalho.

\subsection{Tratamento e análise dos dados}

A pesquisa foi exploratória e qualitativa. Ambos os grupos de foco foram analisados através de análise de conteúdo, sujeita à interpretação do pesquisador. Os dados qualitativos buscam identificar os fatores que influenciam 
essas consumidoras no consumo do luxo, através do que foi dito nos grupos de foco. Também se buscou identificar atitudes, motivações, sensações e sentimentos associados ao consumo e considerando-se com foco privilegiado o meio e a classe de renda em que as informantes se enquadram. Foi realizada uma categorização prévia quanto à renda, usando-se a escala da Abep, para facilitar a análise e a coleta de dados dentro de cada grupo de foco.

Todos os conteúdos colhidos foram analisados em cada grupo de foco. Foram considerados os assuntos que sofreram mais impacto de acordo com as interpretações do pesquisador para, a partir do que as informantes revelaram para criar as categorias que se mostraram mais produtivas para sustentar as conclusões da análise. Objetivou-se, assim, alinhar as informações expostas das informantes de diferentes classes de renda pesquisadas correlacionado as respostas num mesmo contexto, levantando hipóteses e conclusões ao estudo, a partir do referencial teórico.

Foram consideradas na análise: o ambiente e o clima dos debates, olhares das participantes, gestos e suas respostas aos questionamentos realizados. Esta forma de tratar os dados coletados permite evitar que fatores importantes passem despercebidos.

\subsection{Limitações do Estudo}

$\mathrm{Na}$ etapa de grupos de foco deve-se considerar que as entrevistadas podem não ter sido coesas nas respostas do questionário ABEP, participando de um grupo de foco diferente do de sua classe de renda, interferindo assim nas informações do grupo de foco da respectiva classe social. Como a autora tem o assunto muito intrínseco é possível que possa não perceber pequenos detalhes passados pelas entrevistadas no grupo de foco, deixando de levantar determinados pontos.

Por ser uma pesquisa com quantidade limitada de pessoas, pode não se expressar verdade quando comparada a uma população de maior quantidade de indivíduos. 


\section{Apresentação e análise dos resultados}

Este capítulo, organizado em duas seções apresenta e discute os principais resultados alcançados, analisa e relaciona suas implicações e produz sugestões sobre o estudo previamente selecionado.

Está organizado em duas seções. A primeira apresenta e descreve a o perfil das entrevistadas. A seguir trata-se de apresentação e exposição das análises realizadas a partir de categorias criadas do que foi dito nos três grupos de focos realizados das respectivas classes de renda estudadas.

\subsection{Perfil das participantes dos grupos de foco}

\subsubsection{Grupo de foco 1 - Informantes de classe de renda C}

O 1음 grupo de foco reuniu 5 mulheres com idade entre 29 e 56 anos, com pontuação acumulada de cada participante entre 25 e 27 pontos de acordo com respostas coletadas no questionário do critério ABEP (anexo 1). De acordo com critério, todas estão, portanto, estão enquadradas na classe de renda $\mathrm{C}$, onde a faixa de pontuação é de 17 até 28 pontos.

Tabela 1: Dados das participantes do grupo de foco 1

\begin{tabular}{|c|c|c|c|c|}
\hline \multicolumn{5}{|c|}{ GRUPO DE FOCO CLASSE DE RENDA C } \\
\hline No & \multicolumn{1}{|c|}{ NOME } & Idade & Pontuação & Usa MK ${ }^{\circledR}$ \\
\hline 1 & Alessandra & 41 & 25 & X \\
\hline 2 & Erika & 29 & 28 & X \\
\hline 3 & Marlene & 56 & 24 & \\
\hline 4 & Talita & 34 & 26 & x \\
\hline 5 & Thais & 28 & 27 & x \\
\hline
\end{tabular}

As participantes foram questionadas quanto à utilização da marca Michael Kors, para que posteriormente pudesse ser feita uma comparação entre os grupos estudados. Neste grupo pode-se observar uma concentração de uso de bolsas da marca em foco: 4 das 5 participantes.

\subsubsection{Grupo de foco 2 - Classe de renda B}

O $2^{\circ}$ grupo de foco também reuniu 5 mulheres, com as idades das participantes variando de 21 a 25 anos e com pontuações acumuladas no critério 
Abep de 35 a 44 pontos. De acordo com critério, todas estão enquadradas na classe de renda $B$, onde a faixa de pontuação é de 29 até 44 pontos.

Tabela 2: Dados das participantes do grupo de foco 2

\begin{tabular}{|c|l|c|c|c|}
\hline \multicolumn{5}{|c|}{ GRUPO DE FOCO CLASSE DE RENDA B } \\
\cline { 1 - 3 } No & NOME & Idade & Pontuação & Usa MK ${ }^{\circledR}$ \\
\hline 6 & Aluane & 22 & 35 & \\
\hline 7 & Ana Claudia & 25 & 44 & \\
\hline 8 & Barbara & 23 & 37 & $\mathrm{x}$ \\
\hline 9 & Gabriela & 21 & 44 & $\mathrm{x}$ \\
\hline 10 & Lilian & 23 & 43 & $\mathrm{x}$ \\
\hline
\end{tabular}

As participantes também foram questionadas quanto à utilização da marca Michael Kors atualmente. Neste grupo pode-se observar uma utilização da marca por 3 das 5 participantes.

\subsubsection{Grupo de foco 3 - Classe de renda $A$}

Por fim, o $3^{\circ}$ grupo de foco reuniu 3 mulheres, e que as idades das participantes variaram de 34 a 51 anos, com pontuações pelo critério ABEP de 49 a 60 pontos. De acordo com critério todas estão enquadradas na classe de renda $A$, aonde a faixa de pontuação vai de 45 a 100 pontos.

Tabela 3: Dados das participantes do grupo de foco 3

\begin{tabular}{|l|c|c|c|c|}
\hline \multicolumn{4}{|c|}{ GRUPO DE FOCO CLASSE DE RENDA A } \\
\hline No & NOME & Idade & Pontuação & Usa MK ${ }^{\circledR}$ \\
\hline 11 & Camila & 34 & 59 & \\
\hline 12 & Regina & 51 & 49 & \\
\hline 13 & Paula & 42 & 60 & \\
\hline
\end{tabular}

As participantes também foram questionadas quanto à utilização da marca Michael Kors. Neste grupo nenhuma das participantes faz uso atual da marca em questão, o gráfico abaixo ilustra isto:

\subsection{Descrição e análise dos resultados dos grupos de foco}

\subsubsection{Significados do Luxo}

A primeira pergunta foi sobre a palavra luxo e o que essa palavra significava para as participantes. De acordo com Strehlau (2008) luxo tem como referência aquilo que é raro, exclusivo ou caro, contrapondo à necessidade. $A$ maioria das entrevistadas dos três grupos de foco mencionaram pelo menos um desses pontos ou o conjunto deles.

"Eu acho que luxo é algo que não é uma necessidade. Luxo é comprar algo com valor acima do mercado" (E5, classe de renda C) 
O significado do luxo mudou ao longo da história, principalmente em decorrência da evolução material, transformando o que era luxo de uma determinada época em necessidade para outra (D'ANGELO, 2006). Algo que se aproxima muito da fala das entrevistadas classe de renda $\mathrm{C}$ :

"Luxo é uma pessoa bem arrumada, com uma boa bolsa, uma roupa de grife. Isso pra mim, isso é luxo! Tem gente que não vive sem isso, transformando o luxo em necessidade." (E4, classe de renda C) "Me remete a supérfluo." (E2, classe de renda $\mathrm{C}$ )

Para a classe de renda $\mathrm{C}$, luxo é algo que ultrapassa a ideia de necessidade, ligado ao supérfluo, ser caro. Alguém que usa luxo pra elas são mulheres que merecem ser admiradas "Tem bom gosto" (E4), são "Finas e chiques" (E5). Elas ligam ainda o conceito de luxo a produtos, provavelmente como forma de tangibilizar o conceito para elas, o qual muitas vezes precisa ser associado a uma marca ou produto, a um objeto tangível para ser compreendido. Tal processo foi muito utilizado pelas respondentes desta classe de renda.

Para a classe de renda B o luxo tem correlação com qualidade, valor monetário e exclusividade. Elas também tocaram no ponto de se opor à necessidade, mas com muito maior vigor do que as respondentes da classe de renda $\mathrm{C}$, informando, por exemplo, que o luxo e o consumo de suas marcas não são tão importantes pra elas, como é para a classe de renda $C$. Tais questões põem em foco considerações sobre o quão diferente o significado do luxo é para cada um dos grupos estudados.

"Caro" (E6, classe de renda B) "Exclusividade" (E10, classe de renda B) "Produtos de qualidade. Você pensa: estuo pagando mais caro, porque com certeza esse produto é um pouquinho melhor, então não necessariamente ele é, mas a gente espera que seja dessa forma" (E7, classe de renda $B)$ "Luxo pra mim não que seja exagero, mas é você querer uma coisa além do necessário" (E9, classe de renda $B)$

Já para a classe de renda $\mathrm{A}$ o luxo está mais associado a experiências e aos sentimentos que essas experiências adicionam em suas vidas. Percebe-se que pra elas o ter não tem tanta importância quanto para as demais informantes (de renda $\mathrm{B}$ e $\mathrm{C}$ ) abordadas, talvez por já consumirem itens desse mercado há mais tempo. O luxo para as informantes de renda A é descrito por palavras, como: conforto, estar com a família e poder tirar férias para viajar, o que vai ao encontro do que afirma Diniz (2012) que menciona que luxo é algo que estamos 
mais longe de alcançar. Diniz (2012) menciona ainda os mesmos termos das entrevistadas, como: ter tempo com a família, ter tempo para o ócio, ter a oportunidade de fazer viagens inesquecíveis com amigos, por exemplo. E, quando falam do consumo de itens elas atribuem não a uma marca em específico mais sim a atributos de qualidade fornecidos por algumas empresas.

"Luxo pra mim é muito diferente, eu trabalho muito, então luxo pra mim é tomar café da tarde em casa, comer pão [...]. Pra gente que trabalha muito e não tem tempo luxo é isso. Luxo pra mim é estar com a minha família. É passar mais tempo com eles."

$(E 12$, classe de renda $A)$ "Luxo pra mim é conforto." (E13, classe de renda $A)$ "Luxo com certeza tá ligado a uma coisa cara, onde é bem valorizada financeiramente falando, mas leva em consideração também o que é sentimental [...]. Eu vejo luxo das duas formas, pra mim o luxo é realmente tirar férias, porque eu adoro viajar e quando a gente se refere a uma coisa luxuosa é uma coisa cara, fora do padrão normal." (E10, classe de renda $A)$

A fala da entrevistada E10 nos remete a um conceito discorrido por Strehlau (2008) que nos informa que o termo luxo trata-se também de um adjetivo associado a um substantivo, com o intuito de qualificar algo distanciando da ideia do que seria comum ou normal. A participante E10 menciona que coisas luxuosas saem do padrão considerado normal pra ela, atuando de fato como um adjetivo, qualificando seu consumo, portanto.

Pelas respostas das respondentes da classe de renda $A$, percebemos que elas vivem muito mais a ideia do novo luxo, do que as das demais classes de renda, nos termos de Diniz (2012), em que o luxo se situa mais no âmbito do pertencer e experienciar do que ao ter, comprar e possuir. Corrobora, portanto, a ideia de que hoje as classes de maior renda preferem se diferenciar vivendo experiências e não necessariamente em despertar inveja no outro por uso de determinado bem material ou serviço. Seria, assim, mais uma visão narcisista, um deleite sobre si mesmo (LIPOVETSKU e ROUX, 2012).

\subsubsection{Marca de luxo}

A segunda pergunta foi sobre quais marcas as participantes consideravam como sendo de luxo e quais atributos uma marca teria que ter para ser de luxo na percepção delas. Já a terceira pergunta buscava saber se elas compravam itens de marcas famosas e, em caso positivo, quais seriam essas marcas e qual 
o porquê dessa escolha específica? Conforme Strehlau (2008) a decisão de consumir uma marca não se dá apenas pelas características físicas de seus produtos, mas também pela personalidade, potencial simbólico e valores que a marca representa. Todos esses fatores foram bastante explorados nos grupos de foco das classes de renda $B$ e $C$, onde as mulheres apresentaram as suas percepções a respeito do valor das marcas, relacionando com o consumo que faziam daquelas marcas. Esses atributos de ligação foram menos valorizados pelas participantes do grupo de foco da classe de renda A que consideram menos o uso de produtos apenas por sua respectiva associação a uma marca.

"Pra uma marca ser de luxo, ela tem que ter qualidade, preço alto" (E5, classe de renda C) "Vitor Hugo" (E3, classe de renda C) "É mais questão de nome mesmo. [...] pra mim marca nem sempre é sinônimo de qualidade." (E2, classe de renda C)

"Porque a marca hoje em dia com esse mercado capitalista que a gente vive, quando você tem a marca, você quer ostentar, você quer mostrar pra todo mundo que você pode, mais que os outros, você tem um diferencial, você não tá igual todo mundo, você tem algo de boa qualidade, você tem um status, te valoriza" (E5, classe de renda C)

O que é informado pela entrevistada E5 nos remete a questão da aspiração social, onde as classes mais populares adquirem bens de luxo com intuito de terem reconhecimento social (LIPOVETSKY e ROUX, 2012). O mesmo termo mostra o poder dos grupos de referência que segundo Solomon (2011) operam quando uma pessoa admira e tenta imitar as qualidades de outros. Isso ocorre emulando o comportamento de alguém ou de um grupo, como por exemplo, escolhendo roupas e marcas associadas ao consumo do grupo imitado. Nesse contexto buscam, através do consumo e da posse e uso de objetos, se diferenciar de outras mulheres que percebe com suas 'iguais' e nesse sentido a entrevistada não quer "ser igual todo mundo". Ela, ao mesmo tempo, não quer ser igual as demais mulheres de sua classe de renda, posto que ela menciona características de um consumo realizado por uma classe de renda mais alta que a sua própria para situar precisamente que "você não tá igual todo mundo" e, assim, afastá-la do pertencimento com sua classe de renda atual. Ela clara e explicitamente admira o consumo de itens associados ao consumo de mulheres com maior poder aquisitivo que o seu próprio, pelas quais ela tenta assimilar o seu consumo, processo explícito em suas falas. 
Quando questionadas sobre comprar itens de marcas famosas, 4 das entrevistadas afirmaram consumir marcas de luxo. Entre os itens comprados foram mencionados, relógios, jeans, bolsas e óculos.

"Eu sempre gostei de relógios e jeans de marca, sempre que posso compro e vou pagando aos poucos. [...] não que eu possa sempre, mais gosto bastante de me presentar" (E5, classe de renda $\mathrm{C}$ ) "Eu tenho loucura na Louis Vuitton, mas já entrei em algumas lojas e é muito caro, ainda não deu pra comprar, mesmo parcelando" (E3, classe de renda C)

"Eu tenho bolsas de marcas, tenho da Vitor Hugo, da Michael Kors, relógio só gosto e só tenho da Michael Kors, não consigo usar outro, porque é qualidade, dura, você fica com ele anos e anos e poxa às vezes você compra sapato de uma Arezzo, uma nativa o negócio dura, dura, dura e quando você pega um da Sapatella usa 3, 4 vezes e joga fora porque ele ficou ruim e o de uma arezzo de uma nativa ele vai durar bem mais. Então assim você paga um pouco mais caro mais tem aquele produto num longo prazo, num longo período" (E4, classe de renda $\mathrm{C}$ ) Para a classe de renda $C$, claramente as bolsas de luxo são as mais conhecidas e famosas no mercado. Elas mostram admiração pelas mesmas e ao mesmo tempo muitas demonstram que possuem algumas delas. Critérios associados á avaliação de bolsas de luxo são levantados como: durabilidade, desejo de possui-las e comparação com outras marcas, mostrando os motivos que as levam a adquirir esses itens, indicando que muitas das vezes o critério é exatamente se distinguir como alguém diferenciado, por exemplo, expresso na questão de durar mais que de marcas menos conhecidas. Dessa forma afirmam que mesmo com valor/preço mais elevado elas preferem marcas de luxo pela qualidade associada, nesse caso associada com durabilidade.

Para a classe de renda $B$, a associação com marca de luxo na maioria das vezes tem relação com o preço cobrado e suas consequências tais como exclusividade, acesso limitado, conhecimento especializado:

"Uma marca super, mega power cara" (E7, classe de renda B) "É aquela que poucas pessoas conseguem adquirir, prestigiar."

(E8, classe de renda $B$ ) "É aquela que é conhecida por muita gente" (E10, classe de renda B)

"Se for tipo um eletrodoméstico, ok, porque eu sei que provavelmente vai durar bem mais que um de uma marca que não é conhecida. Mas agora tipo coisas mais fúteis, uma bolsa sei lá 
ou tipo um sapato acho que é muito mais raro, é coisa tipo uma vez na vida." (E8, classe de renda B)

"Tem produtos que eu valorizo a marca, por exemplo, meu óculos é $R \$ 10$ mil, eu vou dar um jeito de pagar 10 mil porque eu gosto da marca, da armação, eu gosto da marca da lente." (E7, classe de renda B)

"óculos eu compro Rayban, pela questão o filtro solar, não vale a pena comprar um ruim pra estragar a visão, eu consumo a marca quando eu vejo qualidade, durabilidade ou se for um serviço pelo suporte que eu vou conseguir posteriormente em caso de algum problema" (E9, classe de renda $B$ )

"O que eu compro mais de marca famosa, é maquiagem por causa da minha pele, então uso MAC, não porque é uma marca MAC, mais ela têm atributos que são importantes pra mim, como filtro solar, antienvelhecimento." (E10, classe de renda $A)$

"O máximo que eu consumo é perfume, por questão de durabilidade, por questão de fixação. Então eu prefiro pagar mais caro por um perfume que fixa" (E13, classe de renda $A)$

Uma das marcas que as entrevistadas relacionaram a luxo foi a Ray Ban, talvez pela idade e pelo envolvimento com a tecnologia das mesmas. Em geral elas consomem marca quando é algo que realmente vai proporcionar a elas alguma vantagem pelos atributos oferecidos. Assim elas não mostraram preocupação com o pagamento, com o esforço condensado no pagar caro, como enunciado pelas informantes de classe de renda C: "Eu tenho loucura na Louis Vuitton, mas já entrei em algumas lojas e é muito caro, ainda não deu pra comprar, mesmo parcelando" (E3, classe de renda $C$ ), mas com o real sentido para o valor empregado: "Tem produtos em que eu valorizo a marca, por exemplo, meus óculos são de $\mathrm{R} \$ 10$ mil, então eu vou dar um jeito de pagar $\mathrm{R} \$ 10$ mil porque eu gosto da marca, da armação, eu gosto da marca da lente." (E7, classe de renda $\mathrm{C}$ )

As marcas de luxo para a classe de renda $A$ são bem diferentes das apresentadas pelas classes de renda $B$ e $C$. Elas nem sempre associam a marca com a questão da qualidade, diferentemente dos demais grupos de foco, onde o luxo, a durabilidade e a qualidade foram explicitamente associados. Elas mencionaram marcas de roupa de cama, perfumes e lugares para se visitar. $O$ que pode ter sido relevante nas respostas neste caso é a idade das entrevistadas, um pouco mais elevada que as da classe de renda $B$ e um pouco 
mais parecida com a amostra do grupo de foco da classe de renda C. Abaixo há uma tabela com todas as respondentes, classificadas em ordem de idade:

Tabela 4: Comparativo Idade $\mathrm{x}$ utilização marca Michael Kors

\begin{tabular}{|c|c|l|c|c|}
\hline \multicolumn{4}{|c|}{ Idade Entrevistada } & \multicolumn{1}{c|}{ Nomes } \\
\hline 56 & 3 & Marlene, classe de renda C & 24 & \\
\hline 51 & 12 & Regina, classe de renda A & 49 & \\
\hline 42 & 13 & Paula, classe de renda A & 60 & \\
\hline 41 & 1 & Alessandra, classe de renda C & 25 & x \\
\hline 34 & 4 & Talita, classe de renda C & 26 & x \\
\hline 34 & 11 & Camila, classe de renda A & 59 & \\
\hline 29 & 2 & Erika, classe de renda C & 28 & x \\
\hline 28 & 5 & Thais, classe de renda C & 27 & x \\
\hline 25 & 7 & Ana Claudia, classe de renda B & 44 & \\
\hline 23 & 8 & Barbara, classe de renda B & 37 & x \\
\hline 23 & 10 & Lilian, classe de renda B & 43 & x \\
\hline 22 & 6 & Aluane, classe de renda B & 35 & \\
\hline 21 & 9 & Gabriela, classe de renda B & 44 & x \\
\hline
\end{tabular}

De fato na tabela observa-se que a concentração da utilização das bolsas MK está nas mulheres mais jovens. Considerando as 3 primeiras informantes da tabela, percebemos que a única respondente que não utilizava a marca está no mesmo intervalo das respondentes de classe $\mathrm{A}$ e pertence a classe de renda $\mathrm{C}$. Tal constatação sugere então que esse pode ser um fator importante na utilização da marca o que poderia ser melhor trabalhado se no grupo de foco da classe de renda $A$ fosse eventualmente composto por mais mulheres jovens. Isto mais uma vez sugere que o consumo de itens de luxo é influenciado por fatores de ordem social, cultural, psicológico, demográfico e pessoal tal como afirma Diniz (2013).

"Luxo, pra mim me vem logo com o financeiro, luxo é uma coisa cara, eu já tenho isso como na cabeça e acrescentando acho que é o reconhecimento internacional de repente. Uma marca que é reconhecida internacionalmente com certeza vai ser mais cara do que uma marca conhecida apenas num país[...]. "

(E10, classe de renda $A)$ "Algumas vezes está vinculada a qualidade." (E13, classe de renda $A)$ "Uma marca de luxo pra mim é a Trousseau, onde tem roupa de cama com 600 fios." (E10, classe de renda A) Percebemos que conforme mencionado por PARENTE; BARKI e GEARGEOURA (2008) ao analisarmos as classes do topo da pirâmide, o consumo do luxo é voltado para manter o status social e familiar, a exclusividade 
e a qualidade percebida nos produtos, enquanto que as classes mais populares estão interessadas na experiência de aspiração social ao utilizar produtos característicos de classes mais abastadas.

\subsubsection{Disseminação do luxo e a marca Michael Kors}

Os gráficos apresentados no item 4.1 que discorre sobre o perfil das participantes introduzem a análise da sexta pergunta que foi sobre como elas viam a marca Michael Kors.

A partir dos gráficos é possível sugerir que a classe de renda $C$ é a classe que mais consome a marca, seguida pela classe de renda $B$ e sendo a que menos consome a marca a classe de renda A. Por outro lado, a análise do perfil etário das informantes sugere que a idade por exercer papel relevante na prédisposição de uso e consumo da referida marca.

Foi pedido, então, que as entrevistadas descrevessem a marca. A partir de tais relatos foi percebido que a classe $C$ tem completa adoração pela marca, enquanto que as classes A e B não a veem tão enfaticamente como marca associada aos significados do luxo:

"Eu consumo bolsa, tenho mania da Michael Kors [...]" (E1, classe de renda $\mathrm{C}$ ) "Eu compro porque eu gosto, porque é bonito, porque é dourado" (E4, classe de renda $\mathrm{C}$ )

"Eu compro porque eu gosto e pelo diferencial, né? Por que tem coisas que todo mundo tem, gosto sempre de ser diferente, então eu compro mais por isso." (E5, classe de renda C)

"[...] a personagem Carminha, da novela, ela vinha com uma bolsa dourada, [...] ela era uma pessoa bem sucedida, ela andava super chique. Isso fez a cabeça das mulheres, e foi por esse motivo que eu chequei a ter a marca e é por isso que eu tenho até hoje. Não necessariamente quem usa a marca é sempre uma pessoa chique, mas me remete a isso." (E5, classe de renda $\mathrm{C}$ )

"Houve uma época que foi um estouro. Ai ela ficou mega acessível" (E8, classe de renda $B)$

"Hoje em dia acho que tá mais batido, porque todo mundo tem, muita gente comprou" (E9, classe de renda $B)$ "Dessas marcas ela é até a mais acessível" (E13, classe de renda A) Tais relatos estão associados, conforme Strehlau (2008), com o que seriam as alterações do conceito de luxo, com os efeitos que determinadas 
marcas ou objetos sofreriam no decorrer do tempo. Destaca-se aqui o caráter mutável e fugidio, portanto instável da associação de uma determinada marca com imagem de luxo. Para algumas participantes das classes de renda $A$ e $B$ a marca Michael Kors perdeu as características de luxo, muito por conta da acessibilidade facilitada da marca, pela perda progressiva de seu caráter de exclusividade e raridade diferencial. Relatos tais como "Por ela ter ficado acessível e outras classes começaram a usar, perdeu a questão da exclusividade" ( $E 7$, classe de renda B) e "Ela não é tão cara assim." (E6, classe de renda $B$ ) nos remetem a alguns dos atributos relacionado do conceito de luxo, nos termos de Strehlau (2008), como sendo algo raro, exclusivo ou caro. As participantes indicam que a associação desses termos com a marca se enfraqueceu, fazendo com que ela decaísse no que se refere a marca de luxo.

Apesar de o conceito luxo ser estável, os bens nos quais se manifesta são alteráveis, nesse caso tato a bolsa como a marca. A associação com o luxo, portanto, muda por vários fatores seja por contexto histórico, cultura em que se insere e até nas particularidades de cada individuo (STREHLAU, 2008). Dessa forma a renda se torna um fator importante para entender as variações nas associações de marcas diversas ao conceito de luxo na medida em que se percebe uma variação da associação da marca MK com o luxo nos grupos de foco de cada classe de renda. A classe de renda $C$ continua vendo a marca MK como uma diferenciação em seu uso, enquanto que as classes de renda $\mathrm{A}$ e $\mathrm{B}$ a veem como algo ultrapassado e de certa forma banalizado.

"Eu consumo bolsa, tenho mania da Michael Kors [...]" (E1, classe de renda C)

"Num primeiro momento esse boom impulsionou a marca, mas depois trouxe ela pra baixo," (E9, classe de renda $B)$

"Ela parou de ser vista tanto como uma marca de luxo, porque como ela é mais acessível todo mundo compra, por que geralmente as marcas de luxo são aquelas que você olha e você deseja e muitas vezes você não pode ter, no meu ver como luxo ela caiu" (E8, classe de renda B)

"[...] ela era algo que todo mundo queria. Assim quando todo mundo começou a comprar, tipo a marca ficou mais falada, isso foi bom porque ficou mais conhecida, mas também ela perdeu um pouco do status que tinha. Não é uma coisa que: Ah é difícil de conseguir" (E7, classe de renda $B$ ) 
"Eu acho que todas de luxo, ela é até a mais despojada, ela não é nem tão cara, tem relógios bonitos, eu não uso relógio por isso que eu não tenho."

(E10, classe de renda $A)$

A novela Avenida Brasil, embora não tenha sido objeto de nenhum estímulo explicito nem implícito, foi espontaneamente citada pelas mulheres das classes de renda $B$ e $C$, na medida em que a marca MK foi explicitamente exposta em ações de merchandising na novela e marcou o imaginário das participantes dos dois grupos de foco que a mencionaram explicitamente em associação com a marca MK. Na classe de renda B o significado associado ocorreu como algo negativo. Inicialmente perceberam que a exposição da marca na novela ajudou inicialmente a marca MK, mas depois a prejudicou. No grupo de foco de classe de renda $C$ a exposição da maraca na novela está associada $e$ um grande marco para o seu sucesso, o que colabora com o que havia sido informado na introdução sobre a novela e demostra o diferente efeito no imaginário das diferentes classes de renda. $O$ interessante nesse ponto foi que a classe de renda A não mencionou tal fator, talvez por não assistir a novela na época e por a novela não ter sido destinada ao seu público. Por outro lado isso sugere que possivelmente seu conteúdo não viesse a agradá-las. O que nos remete a pergunta de pesquisa e nos sugere que a disseminação do consumo da marca de luxo junto às classes mais populares afeta sim a associação da marca com o luxo para imagem de marca junto a um público de renda mais alta e acaba por desvalorizar a marca usada, mesmo que a médio a longo prazo. Dessa forma a exclusividade deve ser entendida a partir do consumo de grupos específico para caracterizar a associação com o conceito de luxo. Uma abordagem generalista quanto a exclusividade e sua associação ao luxo se mostra bastante precária, portanto, para evidenciar as formas com diferentes públicos articulam significados em seus imaginários peculiares.

\subsubsection{A bolsa e as interações no consumo}

As respostas das perguntas 4, 5 e 7 do roteiro (anexo 2) confeccionado para orientação no decorrer dos três grupos de foco trouxeram pontos semelhantes para análise. Por isto os mesmos foram agrupados nessa categoria por remeterem a temas importantes da análise que perderiam sentindo se analisados separados e tornam-se mais ricos discorridos em conjunto.

$\mathrm{Na}$ quarta pergunta as entrevistadas foram questionadas a falar dos motivos que pra elas levam as mulheres a comprarem uma bolsa de luxo e na 
quinta pergunta o que elas acham dessas mulheres, alguns trechos foram expostos abaixo:

"A mulher que usa esse tipo de bolsa tem dinheiro, ou tem alguém pra bancar" (E6, classe de renda B) "Eu acho que a mulher que usa esse tipo de bolsa é porque ela pode, é porque ela quer e isso é um problema dela." (E8, classe de renda B) "Às vezes nem é porque elas têm dinheiro, às vezes elas trabalham muito, parcelam em 50 vezes pra realizar o que muitas vezes pra elas pode ser um sonho" (E6, classe de renda B)

"Eu acho que ela é uma mulher chique, uma mulher diferenciada, uma mulher de bom gosto. Pra mim entra na questão do ter um bom gosto ou não" (E5, classe de renda C).

"Pra mim uma mulher compra uma bolsa de luxo por ostentação, ou ela precisa se firmar de alguma forma" (E12, classe de renda $A)$

No que foi falado pode-se perceber características intangíveis para essas mulheres, como o "ser diferenciada", "precisar se firmar de alguma forma", "pra elas pode ser um sonho" o que corroborando com a teoria do luxo ser abundante em significado e simbologia, pois são valores passados que muitas das vezes não podem ser quantificados e que são influenciados por valores culturais e individuais (D'ANGELO 2006), ou seja, cada mulher enxerga o consumo de luxo na outra, seguindo suas perspectivas, demonstrando o que elas acreditam individualmente. Percebemos algo relacionado a poder aquisitivo visto pelas respondentes das classes de renda $\mathrm{B}$ e $\mathrm{C}$ como o motivo para consumirem essa bolsa e para a classe de renda $A$ as mulheres usam a marca por ostentação.

"Às vezes nem é porque elas têm dinheiro, às vezes elas trabalham muito, parcelam em 50 vezes pra realizar o que muitas vezes pra elas pode ser um sonho" (E6, classe de renda B)

Esta fala da entrevistada 6 , pertencente a classe de renda $B$ faz referência com o conceito de Johnson (2007) que diz que bolsa carrega fatores relacionados à imagem ideal. Não é simplesmente um produto e sim extensão da identidade da mulher que a usa como uma forma de realização pessoal, pois transforma o objeto que em essência serviria para carregar itens e acessórios em um campo dos sonhos, do desejo e da libertação do cotidiano. Leva as mulheres às vidas que gostariam de ter, podendo transformar uma plebeia em princesa. 
Status foi o termo citado pela maior parte das entrevistadas do grupo de foco da classe de renda $A$ e $B$, sendo o fator mais importante considerada por elas. Elas ainda incrementaram suas análises, com:

"Tem duas bolsas iguais, muito parecidas, uma que é de marca e a outra que é de uma lojinha. Você vai querer a de marca, tudo por uma questão de status" (E8, classe de renda B)

"Já vai inferir que a outra que não é conhecida é inferior do que a de marca." (E10, classe de renda $B)$

A questão da imagem feita das mulheres que usam esse tipo de bolsa também é algo que chama atenção, $\mathrm{Na}$ atual sociedade do capitalismo tardio, assim nomeada por Venturelli (2010), a individualização é exaltada, o que afeta a criação das identidades. Percebemos que cada uma tem uma visão em tese de uma mulher que tem característica em comum, usar bolsas de marca. Tem aquelas que têm completa rejeição e tem aquelas que possuem simpatia, é algo mais individualizado do que um acordo em cada classe de renda.

Quando questionadas se o consumo de outras mulheres, pode influenciar o que elas consomem na questão 7, foram coletadas algumas opiniões, como:

"Eu não sofro esse tipo de influência." (E5, classe de renda $C$ ) "Eu não sou de modinha" (E12, classe de renda $A)$

Transparecendo mais uma questão de orgulho das suas próprias decisões, o que foi revertido posteriormente por algumas classes de renda como a $B$ e $C$ no decorrer do grupo de foco, conforme trechos abaixo:

"Quando você me perguntou se alguém me influenciava [...] existe a modinha, a MK ela veio junto, não sei se vocês se lembram com a personagem da Carminha, da novela, ela vinha com uma bolsa dourada, e foi ali que na verdade, eu que já conhecia a marca, porém não tinha vontade de ter e foi dali que foi o BOOM da marca [...], porque ela era uma pessoa bem sucedida, ela andava super chique. Isso que na verdade fez a cabeça das mulheres, e foi por esse motivo que eu chequei a ter a marca e é por isso que eu tenho. Não necessariamente quem usa a marca é sempre uma pessoa chique, mas me remete a isso." (E5, classe de renda $\mathrm{C}$ ) As mulheres que imitam o comportamento de compra da personagem da novela querendo parecer ter as mesmas características da Carminha, como ainda mencionada por ela, onde as características são: "[...]bem sucedida, super chique[...]" (E5, classe de renda $C$ ) remetem mais uma vez à necessidade de similaridade com os grupos de referência, que de acordo com Solomon (2011) compara os humanos a animais sociais, os quais precisam se sentir 
pertencentes e isso muitos vezes se dá quando nos aproximamos do que é feito por grupos dominantes, o que nos faz sermos aceitos, esse grupos podem ser reais ou imaginários com poder de determinar determinado comportamento a ser seguido/almejado como é feito pela personagem Carminha e pelas demais mulheres citadas pelas entrevistadas, conforme abaixo:

"eu acho que a mídia influencia muito" (E4, classe de renda C)

"Eu acho que não é só a mídia não tá, porque aqui mesmo vejo muita gente olhando coisa um do outro, cara adorei, vou lá ver, até porque mulher tem disso. Eu acho que não é só um personagem, não é só a mídia. A gente mesmo comentou sobre a bolsa. Eu acho que assim

os próprios pares, colegas de trabalho, amigas, eu pelo menos nem sempre eu me liguei em marca, então eu não fico procurando na mídia alguma coisa, pra ver se eu vou gostar. Não., se eu ver uma amiga, caraca, gostei, legal não sei o quê e eu for lá e tiver dentro das minhas condições eu vou comprar e eu acho que acabamos sendo influenciadas dessa forma, pelas pessoas que estão ao seu redor também, não só pela mídia." (E2, classe de renda $\mathrm{C}$ )

"O mundo que você vive te influencia a você ter algo mais caro. $\mathrm{O}$ meio das pessoas que você vive com quem você convive." (E4, classe de renda $\mathrm{C}$ )

"Ah eu vou ser honesta influencia sim, se tá tipo querendo ou não se todo mundo tá usando, influencia um pouco tipo a melissa eu não gostava, mas como via todo mundo usando comprei uma e gostei." (E8, classe de renda $B$ )

"Uma mulher que influencia minhas compras tem Giovanna Antonelli, Thais Araújo, algumas personalidades elas acabam influenciando. Às vezes nós sabemos que muitas vezes usam elas pra nós admirarmos, eu acho que elas influenciam bastante" (E10, classe de renda $B)$

"A mulher que usa a marca altera minha percepção sobre a mesma, eu acho que só não altera quando a fidelidade com a marca já é muito consolidada." (E10, classe de renda B)

Já as mulheres da classe de renda A não tiveram esse tipo de conflito interno, talvez por terem certeza de sua autoimagem e se aceitarem. De acordo com Kotler e Keller (2012) tratam-se das características do comportamento de compra, conjuntos de traços psicológicos que traduzem a identidade de um consumidor, e a classe de renda $A$ possui isso mais certo na cabeça delas a 
respeito de sua imagem do que as mulheres das demais classes. Se quiserem consumir esse não será o único fator observado.

Nesse momento para aprofundar mais as opiniões foi perguntado se elas achavam que o consumo de mulheres da classe de renda $C$ poderia alterar $O$ consumo das mulheres da classe de renda $A$. A entrevistada 13, classe de renda A, mencionou "vamos dizer que ela ganhou da patroa dela" já distanciando o direito de uso por aquela mulher, minimizando-a.

"Elas não querem que todo mundo tenha acesso ao que elas têm." (E13, classe de renda $A)$ "Eu acho que se uma mulher do subúrbio usa uma bolsa que as mulheres do Leblon estão acostumadas a usar, tem a questão da vaidade elas vão parar ou vão diminuir o uso daquela marca, tentando talvez comprar outras marcas. Eu tenho muito o exemplo do ray-ban, que é uma marca que eu sempre usei, sempre gostei e sempre tive óculos da ray-ban e agora você vai num camelô, lança um modelo da ray-ban da coleção nova vai no camelô e tem modelos iguais, lógico que a qualidade nunca vai ser a mesma, mas eu tenho receio à vezes de comprar, eu sempre quando vou comprar algum ou alguma coisa, algum lançamento

eu tento ver sempre um modelo que tem um diferencial que ah não vi num camelô ainda, porque realmente é uma vaidade, eu acho que é uma vaidade, mas você acaba realmente ficando igual a todo mundo e as pessoas acabam podendo achar que você está usando uma coisa falsa."

(E5, classe de renda C)

Logo, independente da classe de renda vemos uma necessidade de distinção social, produtos de luxo são desejados mais por suas características intangíveis do que por sua função utilitária (D'ANGELO 2006). Vemos no uso da classe de renda C o conceito de Barth (1996) quando elas utilizam luxo visam passar uma imagem de pertencimento a um nível superior na hierarquia social, atribuindo uma conotação de que a pessoa faz parte de um grupo distinto numa grande sociedade de massa.

\subsubsection{Representação}

$\mathrm{Na}$ oitava pergunta utilizou-se de técnica projetista através associação de duas fotos a animais, conforme abaixo. As imagens foram apresentadas separadamente as participantes e foi solicitado que contassem histórias a partir daquelas imagens. Posteriormente foi solicitada a associação das imagens com um respectivo animal e se tinha algum motivo para tal associação, deixando 
assim mais descritiva a percepção de cada grupo de foco ao mesmo perfil ao quais ambas as classes de renda foram apresentadas:

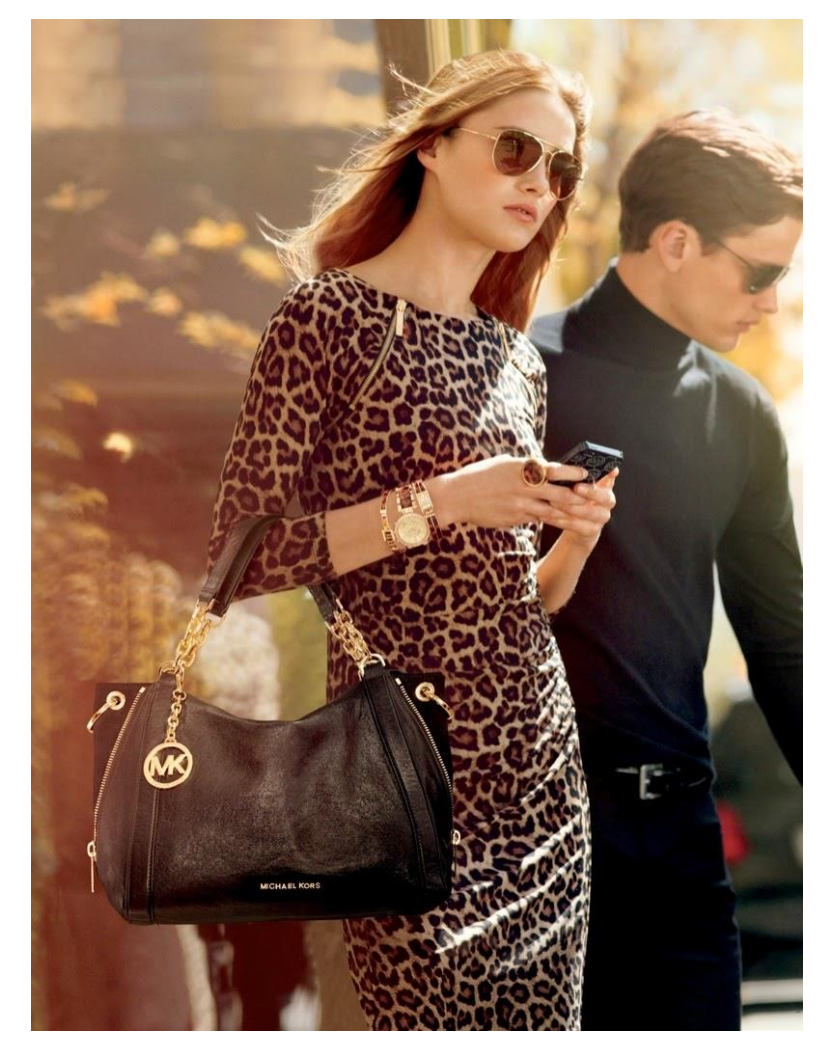

Figura 5: Mulher 1 usando bolsa Michael Kors

Fonte: internet

"Na minha cabeça parece uma mulher moderna, bem vestida, elegante. Até porque quando você mostrou a gente automaticamente reparou a marca da bolsa né. Na verdade ai remete o lance da aparência, na verdade você não sabe se essa mulher é realmente bem sucedida, fina, elegante, educada como parece. Mas pela vestimenta dela, nos remete a isso. A gente pensa que ela é uma mulher elegante, fina educada. Tem um rapaz ali, não sei se está abrindo a porta do carro pra ela. É uma mulher chique, vamos dizer assim, não necessariamente, a gente não sabe se ela é uma mulher chique, mas a aparência dela, pelo que a gente tá verificando, tanto que só enfatizou ela." (E5, classe de renda C) "Elegante, a marca ajuda nesse caso com certeza, que é vista de outra forma. Conheço pessoas que são muito elegantes e não tem condição financeira nenhuma, mas tem senso, tem estilo, então a foto não me remete que ela é uma pessoa rica, mas sim uma pessoa elegante, uma pessoa que sabe se vestir. Ela pode tá saindo saí pra ir pro trabalho, pode 
estar saindo dai pra ir pra um shopping ou pode estar vindo de algum lugar e está chegando em casa, em fim " (E2, classe de renda $C)$ "Ela tem uma postura" (E3, classe de renda $C)$ "Acho que ela tá saindo de um almoço pra uma reunião de trabalho." (E9, classe de renda B) "Parece que ela só tá fazendo um editorial mesmo, tá muito glamorosa é uma situação mais criada." (E8, classe de renda $B$ ) "É mais exibição, tipo uma propaganda. As maiorias das mulheres não saem assim, sai tipo só se tiver muito dinheiro e nem assim se tiver muito, muito dinheiro" (E6, classe de renda $B$ ) "Estampa animal, bolsa da Michael Kors, super elegante. Foto de revista" (E10, classe de renda A)

$\mathrm{Na}$ classe de renda $\mathrm{C}$ todas as informantes afirmam quase que em união que a primeira foto remeteria a um tigre ou a uma onça. A entrevistada 4 justificou a sua escolha "Eu adoro onça, e por ela ser uma mulher bem bonita, bem elegante me remete a uma". Na classe de renda B as participantes associaram a foto a um Leopardo, por ser poderosa e glamorosa. As participantes da classe de renda A assimilaram a foto com onça, por conta da roupa. 

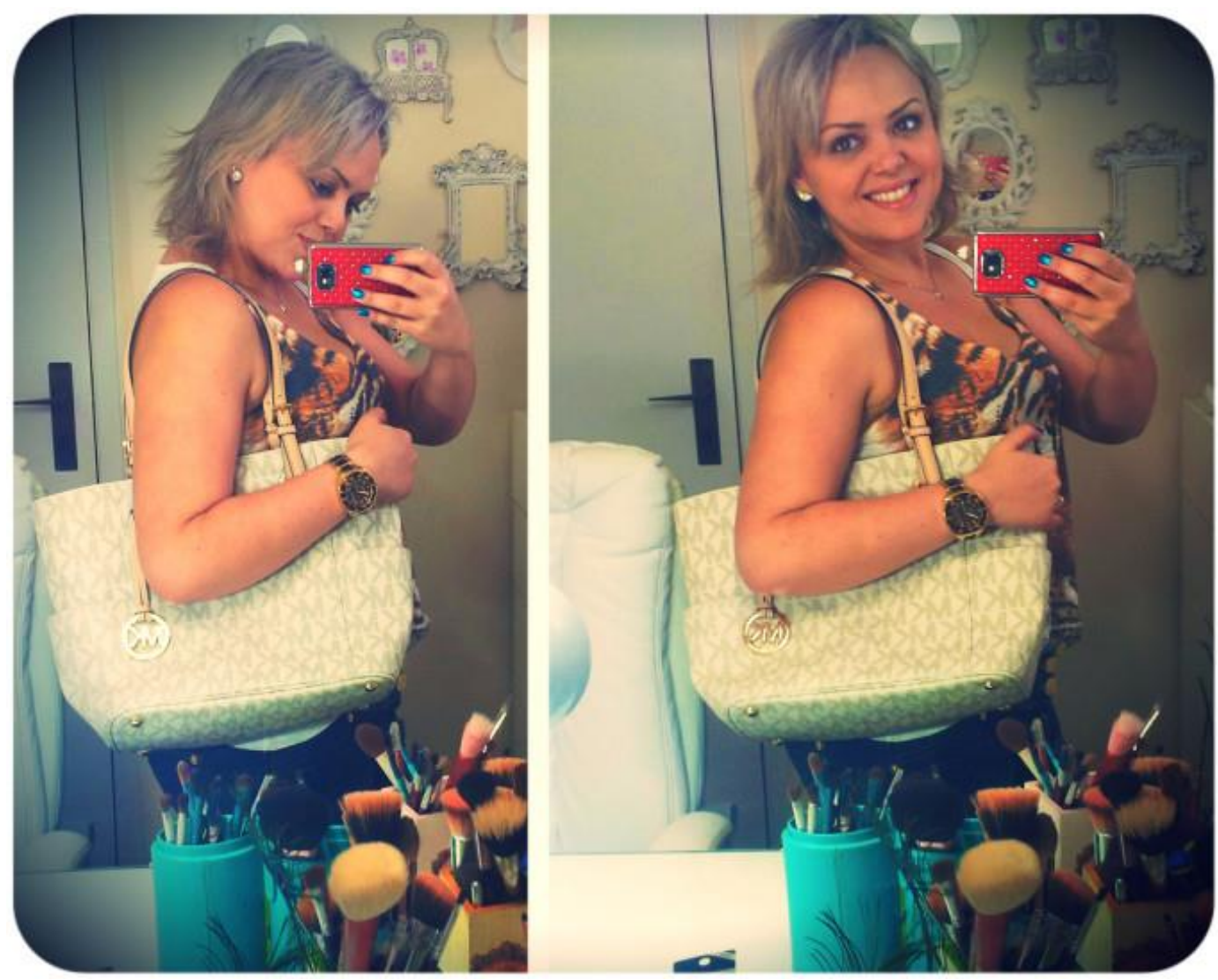

Figura 6: Mulher 2 usando bolsa Michael Kors

Fonte: internet

"Ela tá feliz, porque ela conseguiu obter a bolsa que ela queria como eu Marlene a bolsa. (suspiros)" (E3, classe de renda C) "Parece que nunca teve, ai está querendo se mostrar. Porque quem tem mesmo não mostra." (E5, classe de renda C)

"Comparando as duas fotos, a outra mulher a gente percebe que foi uma foto espontânea não tá mostrando que ela tem, já esse aqui tá mostrando, acredito que para as redes sociais o que ela adquiriu. Entendo o momento dela de felicidade, porém pra mim é uma exposição que eu não

curto."

"Essa mulher tem os mesmo itens da primeira, um celular bom, uma bolsa da mesma marca, mas não tem elegância, não tem postura é muito diferente da primeira." (E2, classe de renda $C)$

"Ela acabou de comprar a bolsa e tá querendo mostrar pra alguém." (E9, classe de renda B)

"”Não é uma coisa natural sabe, tipo olha aqui a minha bolsa" (E10, classe de renda $B$ ) 
"Pra mim as duas fotos remetem a mesma coisa, o exibicionismo. Sendo que a primeira tem mais o teor de propaganda e a outra lutou pra conseguir e ela está feliz com isso" (E8, classe de renda B)

"A segunda parece que lutou mais pra conseguir do que a outra, porque ela tá muito feliz" (E9, classe de renda B)

A segunda foto a classe de renda $C$ associou a um gato em comparativo ao tigre da primeira foto, mostrando talvez certa inferioridade.

A segunda foto as respondentes da classe de renda $B$ associaram a uma hiena porque ela tá muito feliz, a E9 mencionou que ela não é um leopardo, mas Ihe deu a similaridade a uma leoa porque ela conquistou aquilo que ela queria. $A$ classe de renda assimilou a um pavão, pelos enfeites composto segundo ela de forma exagerada na imagem.

"A diferença que uma aparenta ser rica e a outra nem tanto. Uma é rica e a outra é pobre tirando selfie com uma fake ali olha" (E10, classe de renda $A$ )

"Ela quer se promover, você acha que a bolsa é fake só por conta do estilo dela. De repente se essa mulher estivesse bem vestida, poderíamos não achar que se trata de uma bolsa fake. Nessa foto, pelo ambiente, pela postura que ela tá parece que é fake" (E13, classe de renda $A$ )

De repente se ela estivesse com outra roupa, em outro local elas não achariam que se trataria de uma bolsa fake. As respondentes da classe de renda A assimilaram a moça da foto com macaco, pois eles gostam de aparecer e ela também.

Com o uso da técnica projetista podemos analisar que as consumidoras da classe de renda $\mathrm{C}$ veem na mulher da primeira foto algo a se admirar e sonhar, para as mulheres das classes de renda $A$ e $B$ ela já não tem todo esse poder sendo muitas vezes até correlacionada a editorial, algo que não acontece daquela forma no mundo real.

$\mathrm{Na}$ segunda imagem, foi possível constatar certo desprezo por todas as classes de renda, principalmente pela classe de renda $A$, talvez por não entenderem que aquele contexto é mais comum do que se imagina, por estar fora da realidade delas ser algo tão grandioso, elas diminuem a conquista ou acham que se aquela mulher usa a marca, trata-se de um fake, o que pode não ser verdade. 


\section{Conclusões e recomendações para novos estudos}

Este trabalho teve por objetivo analisar e correlacionar o consumo de luxo das bolsas Michael Kors por mulheres das classes de renda A, B e C.

Para tal, houve primeiro uma preocupação em categorizar o que entende por luxo atualmente. Autores como Strehlau (2008) e Lipovetsky e Roux (2012) afirmam que a palavra luxo e o que ela representa tem se alterado com o tempo. $\mathrm{O}$ que antes era restrito a uma pequena parcela privilegiada da sociedade por questão de status e poder progrediu com a história e se disseminou. O luxo foi se transformando em sinônimo de prazer, sentimento de realização e qualidade reconhecida.

Ainda segundo Lipovetsky e Roux (2012), o luxo passou por um processo de democratização a partir dos anos 80 do século $X X$, em que produtos de luxo começaram a se tornar mais acessíveis para classes de renda inferiores, devido a diversos fatores como globalização, ascensão econômica de países emergentes, entre outros.

Para confrontar essas teorias com a realidade foram coletadas informações do mercado e realizadas entrevistas com mulheres que representam cada um dos segmentos estudados por intermédio de grupos focais, de modo a confrontar se o que se observa se confirma na prática.

O que se observou é que o mercado é influenciado muito pela moda e pelas mídias em geral, como, por exemplo, a novela Avenida Brasil que popularizou a marca Michael Kors com a sua personagem Carminha, que era a vilã da obra que pertencia a uma classe de renda privilegiada, mas possuía características mais aparentes em mulheres de classe inferior a ela.

O público entrevistado separa seus pontos de vista da seguinte forma: as mulheres de classe de renda mais alta como as classes $A$ e $B$ afirmam que consumir luxo, como as bolsas da Michael Kors, é mais voltado para o conforto e lazer enquanto que as de classes mais baixas, como a classe c, o sentido de comprar essa mesma marca está no fato de elas se realizarem como mulheres diferenciadas das demais de sua própria faixa de renda, cabendo um sentimento de ascensão social que só o consumo de produtos deste tipo proporciona. 
Dessa forma, as mulheres consomem bolsas de luxo para se distinguirem uma das outras e pela questão da qualidade e durabilidade das mesmas. Porém, o consumo de cada classe influencia a percepção da marca para a outra, como evidenciado na sétima pergunta da entrevista, em que as mulheres de renda mais alta deixam de perceber a qualidade da bolsa de grife por esta estar mais acessível atualmente a classes mais baixas. Em contrapartida, mulheres de classes de renda inferiores se interessam em consumir para ter a sensação de pertencer à outra classe superior a sua ao utilizar o produto de luxo, e assim, se diferenciar das suas semelhantes em classe de renda.

\subsection{Sugestões e recomendações para novos estudos}

Como desdobramentos futuros, essa linha de estudo pode ser desenvolvida através de investigação sobre o fator idade das participantes e não apenas a questão das classes de renda a qual elas pertencem, pois pelas análises foi vista provável importância desse fator, o qual pode vir a ser comprovado com uma amostra em maior quantidade de participantes. Com uma quantidade maior de entrevistados, pode-se haver um aprofundamento dos estudos aqui apresentados.

O conceito de luxo é muito complexo e como foi observado tende a ser mutável. As principais mudanças no consumo de luxo datam menos de 40 anos, o que é um período muito curto em termos históricos, logo ainda pouco conhecidos e estudados quanto a seus impactos.

Por fim, este trabalho pode vir a auxiliar empreendedores, empresas e acervos acadêmicos no que se refere ao novo luxo ou luxo contemporâneo. 


\section{Referências Bibliográficas}

Associação Brasileira de Empresas de Pesquisa (ABEP). Critério Brasil 2015 e atualização da distribuição de classes para 2016. São Paulo, 2016. Disponível em: < http://www.abep.org/Servicos/Download.aspx?id=12 > Acesso em 13/11/2016.

BARTH, C. A. S. M. Marketing de produtos de luxo: simbolismo, marcas e estratégia. Biblioteca Digital FGV. São Paulo, p. 123. 1996.

BAUMAN, Z. Identidade. Tradução de Carlos Alberto Medeiros. Rio de Janeiro: Jorge Zahar, 2005.

BLACKWELL, R. D.; MINIARD, P. W.; ENGEL, J. F. Comportamento do consumidor. 9. ed. São Paulo: Pioneira Thomson Learning, 2005.

BRITTO, A. Michael Kors: Ama ou odeia?!. Starving. São Paulo, 04 de jun. 2014. Disponível em: < http://starving.com.br/2014/michael-kors-ama-ou-odeia/ >. Acesso em 13/11/2016.

D'ANGELO, A. C. Precisar, não precisa: um olhar sobre o consumo de luxo no Brasil, São Paulo: Lazuli. 2006.

DINIZ, C. O mercado do luxo no Brasil: Tendências e Oportunidades. São Paulo: Seomam, 2012.

Ferreirinha, C. Os países emergentes se tornam importantes para o luxo! MCF Consultoria, São Paulo, 08 de nov. 2016. Disponível em: <http://www.mcfconsultoria.com.br/material/artigoGazetaEmergentes.pdf >. Acesso em 08/11/2016.

Ferreirinha, C. Mercado de luxo cresce mesmo com a crise. FecomércioSP, São Paulo, 17 de mai. 2016. Disponível em: < http://www.fecomercio.com.br/noticia/mercado-de-luxo-cresce-mesmo-com-acrise $>$ Acesso em 12/11/2016.

FIRAT, F. A.; DHOLAKIA, N.; VENKATESH, A. (1995). Marketing in a postmodern world. European Journal of Marketing, Vol. 2,. 1, 40-56.

GLENIA, F. Michael Kors, grife da 'bolsa da carminha' desembarca no Brasil. G1. São Paulo, 04 de set. 2012. Disponível em: < http://g1.globo.com/economia/negocios/noticia/2012/09/michael-kors-grife-dabolsa-da-carminha-desembarca-no-brasil.html > Acesso em 13/11/2016.

JOHNSON, A. Malas: o poder de um acessório. 1. ed. [S.I.]: H. F. Ullman, 2007. p. 486

JUGGESSUR, J. Luxury Designer Handbag or Counterfeit? An Investigation into the Antecedents Influencing Women 's Purchasing Behaviour of Luxury Designer 
and Counterfeit Brands A thesis submitted for the degree of Doctor of Philosophy By Joshie Juggessur Brunel Busine. 2011. Brunel University, 2011.

KOTLER, P.; KELLER, K. - Administração de Marketing - 14ed. São Paulo: Pearson Education do Brasil, 2012.

LIPOVETSKY, Gilles; ROUX, Elyette. O Luxo Eterno: da idade do sagrado ao tempo das marcas. São Paulo: Companhia das Letras, 2012.

LORDA, N. J. Conceito de identidade: contextos, traços e pertinências na vida organizacional. Escola de Administração de Empresas de São Paulo da Fundação Getúlio Vargas. São Paulo, p. 185. 2011.

Marcela Kawauti - Classe C gasta mais com luxo. Disponível em: http://www.diariodaregiao.com.br/economia/classe-c-gasta-mais-com-luxo-

$\underline{1.153270}$ Acesso em 01/10/2016

PARENTE, Juracy; BARKI, Edgard; GEARGEOURA; Lucien - Varejo: Luxo x Baixa renda. FGV Biblioteca digital, 01 de jan. 2008. Disponível em: < http://bibliotecadigital.fgv.br/ojs/index.php/gvexecutivo/article/download/34077/32 $\underline{886}>$. Acesso em 12/11/2016

PERES, L. A bolsa da Carminha. Veja Rio. Rio de Janeiro, 19 de jun 2012. Disponível em: < http://vejario.abril.com.br/materia/cidade/bolsa-carminha-

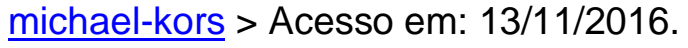

Roland H. A MCF - Carlos Ferreirinha. MCF Consultoria. São Paulo. Disponível em: < http://www.mcfconsultoria.com.br/website/a mcf/carlos ferreirinha > Acesso em: 15/11/2016.

Sociedade brasileira de Proteção ao Crédito (SPC Brasil). O significado do luxo para os brasileiros: Experiência e consumo. São Paulo, 2015. Disponível em:

https://www.spcbrasil.org.br/uploads/st imprensa/mercado de luxo analise1.pdf $>$ Acesso em 14/11/2016.

SOLOMON, M. - O comportamento do Consumidor: Comprando, possuindo e sendo - Porto Alegre: Bookman, 2011.

STREHLAU, S. Marketing de Luxo. São Paulo: Cengage Learning, 2008. Pags 23-30

VENTURELLI, S. O. M. A formação de identidades a partir das mídias virtuais. CEPPG - Centro de Extensão, Pesquisa e Pós-graduação, Catalão, n. 22, p. 924, $1^{\circ}$ Semestre 2010. ISSN 1517/8471. 


\section{Anexo 1}

\section{Questionário para classificação da classe de renda}

(Nome do entrevistado) Agora vou fazer algumas perguntas sobre itens do domicilio para efeito de classificação econômica. Todos os itens de eletroeletrônicos que vou citar devem estar funcionando, incluindo os que estão guardados. Caso não estejam funcionando, considere apenas se tiver intenção de consertar ou repor nos próximos seis meses.

\section{Observação: Todos os itens foram perguntados pelo entrevistador e respondidos pelo entrevistado.}

Vamos começar? No domicílio tem (LEIA CADA ITEM)

\begin{tabular}{|c|c|c|c|c|c|}
\hline & & QUA & DAD & QUE & sssu \\
\hline ITENS DE CONFORTO & $\begin{array}{c}\text { NÃOO } \\
\text { POSSUI }\end{array}$ & 1 & 2 & 3 & $4+$ \\
\hline $\begin{array}{l}\text { Quantidade de automóveis de passeio exclusivamente para } \\
\text { uso particular }\end{array}$ & & & & & \\
\hline $\begin{array}{l}\text { Quantidade de empregados mensalistas, considerando apenas } \\
\text { os que trabalham pelo menos cinco dias por semana }\end{array}$ & & & & & \\
\hline Quantidade de máquinas de lavar roupa, excluindo tanquinho & & & & & \\
\hline Quantidade de banheiros & & & & & \\
\hline $\begin{array}{l}\text { DVD, incluindo qualquer dispositivo que leia DVD e desconsideran } \\
\text { DVD de automóvel }\end{array}$ & & & & & \\
\hline Quantidade de geladeiras & & & & & \\
\hline Quantidade de freezers independentes ou parte da geladeira duple & & & & & \\
\hline $\begin{array}{l}\text { Quantidade de microcomputadores, considerando computadores } \\
\text { de mesa, laptops, notebooks e netbooks e desconsiderando tablet } \\
\text { palms ou smartphones }\end{array}$ & & & & & \\
\hline Quantidade de lavadora de louças & & & & & \\
\hline Quantidade de fornos de micro-ondas & & & & & \\
\hline $\begin{array}{l}\text { Quantidade de motocicletas, desconsiderando as } \\
\text { usadas exclusivamente para uso profissional }\end{array}$ & & & & & \\
\hline $\begin{array}{l}\text { Quantidade de máquinas secadoras de roupas, considerando lava } \\
\text { e seca }\end{array}$ & & & & & \\
\hline
\end{tabular}


A água utilizada neste domicílio é proveniente de?

\begin{tabular}{|l|l|}
\hline 1 & Rede geral de distribuição \\
\hline 2 & Poço ou nascente \\
\hline 3 & Outro meio \\
\hline
\end{tabular}

Considerando o trecho da rua do seu domićlio, você diria que a rua é:

\begin{tabular}{|l|l|}
\hline 1 & Asfaltada/Pavimentada \\
\hline 2 & Terra/Cascalho \\
\hline
\end{tabular}

Qual é o grau de instrução do chefe da família? Considere como chefe da família a pessoa que contribui com a maior parte da renda do domicílio.

\begin{tabular}{|l|l|}
\hline \multicolumn{1}{|c|}{ Nomenclatura atual } & \multicolumn{1}{c|}{ Nomenclatura anterior } \\
\hline Analfabeto / Fundamental I incompleto & Analfabeto/Primário Incompleto \\
\hline $\begin{array}{l}\text { Fundamental I completo / Fundamental II } \\
\text { incompleto }\end{array}$ & $\begin{array}{l}\text { Primário Completo/Ginásio } \\
\text { Incompleto }\end{array}$ \\
\hline $\begin{array}{l}\text { Fundamental completo/Médio } \\
\text { incompleto }\end{array}$ & $\begin{array}{l}\text { Ginásio Completo/Colegial } \\
\text { Incompleto }\end{array}$ \\
\hline Médio completo/Superior incompleto & $\begin{array}{l}\text { Colegial Completo/Superior } \\
\text { Incompleto }\end{array}$ \\
\hline Superior completo & Superior Completo \\
\hline
\end{tabular}




\section{Anexo 2}

\section{Roteiro de apoio para o grupo de foco}

1) O que é luxo para vocês?

2) O que vocês consideram como sendo uma marca de luxo?

3) Vocês costumam comprar itens de marcas famosas? Quais? Por quê?

4) Porque pra você uma mulher compra uma bolsa de luxo?

5) O que vocês acham de uma mulher que usa essa bolsa?

6) Vocês conhecem a marca Michael Kors? Como é a marca? Descreva.

7) O consumo de outras mulheres influenciam no que você compra? Quais mulheres? Isso afeta a sua forma de ver a marca?

8) Conte uma história a partir das fotos abaixo, o que elas the remetem? Se essa bolsa fosse um animal, que animal seria? Por quê?

\section{Imagens utilizadas na discussão do grupo de foco}

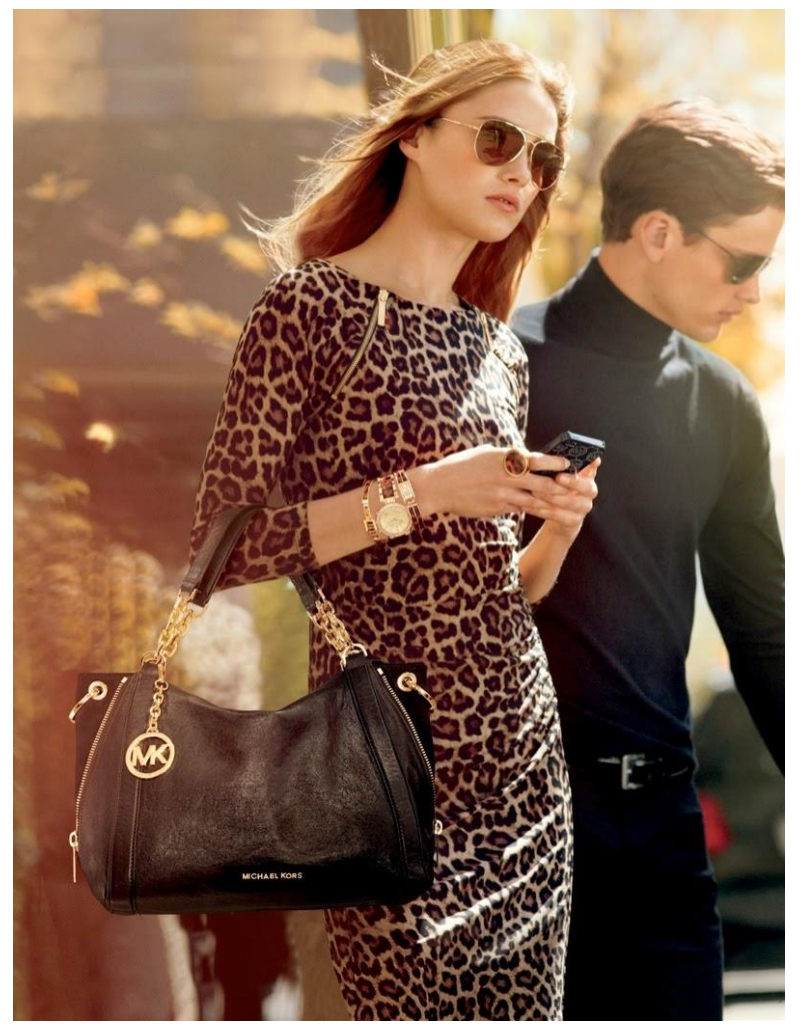

Figura 7: Foto 1 grupo de foco

Fonte: Internet 

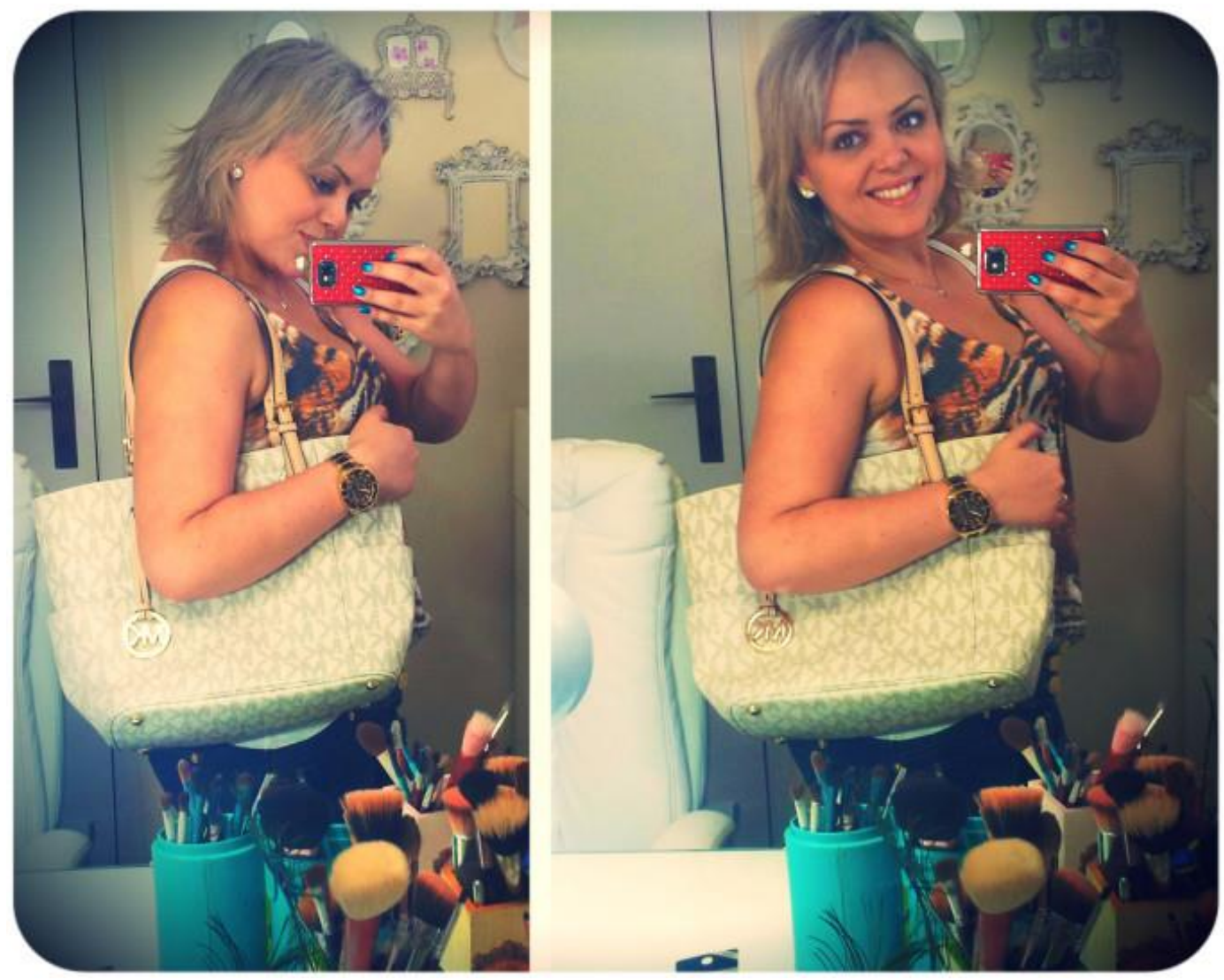

Figura 8: Foto 2 grupo de foco

Fonte: Internet 